\title{
A high resolution tidal model for the area around The Lofoten Islands, Northern Norway
}

\author{
H. Moe, A. Ommundsen, and B. Gjevik*
}

April 27, 2000

\begin{abstract}
A numerical model with grid resolution $500 \mathrm{~m}$ has been used to simulate tides around The Lofoten Islands in northern Norway. The model spans more than $3^{\circ}$ latitude and covers a sea area of approximately $1.2 \cdot 10^{5} \mathrm{~km}^{2}$. The fine spatial resolution resolves the important fine scale features of the bottom topography on the shelf and the complex coastline with fjords and islands. Boundary conditions at the oceanic sides of the model domain are obtained by interpolation from a large scale tidal model covering the Nordic Seas. The semi-diurnal components $M_{2}, S_{2}$ and $N_{2}$ and the diurnal component $K_{1}$ are simulated. Harmonic constants for sea level are compared with observations from 21 stations. The best fit is found for the $M_{2}$ component with a standard deviation between the observed and modelled amplitude and phase of respectively $2.3 \mathrm{~cm}$ and 2.5 degrees. The standard deviation for the other smaller components ranges $1.5-2.8 \mathrm{~cm}$ and $5.3-$ 16.7 degrees. Current fields from the model are compared with observations in four locations; the Moskenes sound, the Gimsøy channel, the Tjeldsund channel and the Sortland channel. Current speed is found to be in good agreement with observations. In the Sortland channel the model predicts a dominant diurnal $K_{1}$ current in agreement with observations.
\end{abstract}

\section{Introduction}

In the Vestfjorden area inside The Lofoten Islands in northern Norway the ArctoNorwegian cod stock spawns from February to March. Here rich fisheries of great economic importance have taken place since early medieval times. In the 13 th. century trading of cod products from Lofoten consolidated the influence and power of the Hanseatic League. The fact that oceanographic elements to a large extent determine the environment for cod spawning and development of eggs and larvae in the Vestfjorden area was realized early, (Eggvin 1932;1934; Sverdrup 1952). Since then there have been several studies of the hydrography and the general circulation in the area. The effect of atmospheric forcing was investigated by Furnes and Sundby (1981). McClimans and Nilsen (1991) studied the circulation by a laboratory model. An extensive NATO field measurement campaign, Rocky Water, has also been conducted (Jenserud 1995;1996) accompanied by data analysis and model simulations (Melsom 1997).

\footnotetext{
*Department of Mathematics, University of Oslo, P.O. Box 1053, 0316 Blindern, Oslo, Norway
} 
Although the tides represent an important part of the current variability in the area, no systematic study of the dynamics of the tides has been reported. Results from coarser grid modelling of tides on the Norwegian continental shelf can be found in Gjevik et al. (1990), Gjevik (1990) and some results of the high resolution model for the main semi-diurnal component $M_{2}$ have been published by Gjevik et al. (1997).

Outside The Lofoten Islands the main semi-diurnal tide is basically a northward propagating wave modified by the topography of the shelf and the coastline. The narrowing of the shelf from a relatively broad shelf south of Lofoten to a narrow shelf on the northern side of the islands and the deflection of the flow due to the island chain itself lead to strong cross-shelf tidal currents near The Lofoten Point (Lofotodden). This local topographic enhancement of the current may play an important role in the transport of eggs and larvae from Vestfjorden to the outer shelf where they are carried northward by the prevailing shelf edge current (Adlandsvik and Sundby 1994; Ommundsen 1999).

In the Moskenes sound, between The Lofoten Point and the island Mosken, a particular strong tidal current, Moskstraumen, runs with speed up to $5 \mathrm{~m} / \mathrm{s}$ (Norwegian Hydrographic Service 1986a). Also in the sounds between the islands east of Lofotodden there are strong tidal currents especially in Nappstraumen and Gimsøystraumen. Rumors of the strength and power of Moskstraumen inspired the authors Edgar Allen Poe and Jules Verne to fantasy descriptions of a Maelstrom whirlpool. Historic accounts of the Lofoten Maelstrom can be found in Gjevik et al. (1997) and Gjevik (1998). The fine structure of the current in the area has also been revealed by ERS-1 SAR (Wahl 1995; Dokken and Wahl 1995) and by SST signals from AVHRR imagery (Mitchelson-Jacob 1995). High resolution SAR images also show that wind waves and swell in the area around The Lofoten Point are strongly modified by depth and current refraction (Krogstad, private communication 1999; Neef 1999).

This paper gives a comprehensive presentation and documentation of the results obtained with a high resolution tidal model for the area. The model span more than $3^{\circ}$ latitude and covers a sea area of approximately $1.2 \cdot 10^{5} \mathrm{~km}^{2}$ (figure 1 ). With a spatial resolution of $500 \mathrm{~m}$ the model resolves both important fine scale features of the bottom topography on the shelf and the complex coastline with fjords and islands (figure 2). This enables a study of the transition of the tide from basically a northward progressive wave on the shelf to standing oscillations in the fjord basins, and the enhancement of the tidal current in the Moskenes sound and other major currents in the area.

High resolution tidal modelling for shelf and coastal areas with complex bathymetry and coastline is a challenging and rapidly developing subject. A review of the state of the art is given by Davies et al. (1997a;1997b). In particular the treatment of strong non-linear effects such as turbulence, flow separation and eddy formation is a difficult task which requires special precautions (Geyer 1993; Maddock and Pingree 1978). Although this model study aims specifically towards an understanding of the dynamics of the tides in the Lofoten area many of the problems accounted here are of wider interest.

A similar high resolution model, as used in this study, has recently been developed for the the coast of Møre and Trøndelag, Mid Norway (Moe et al. 2000). 


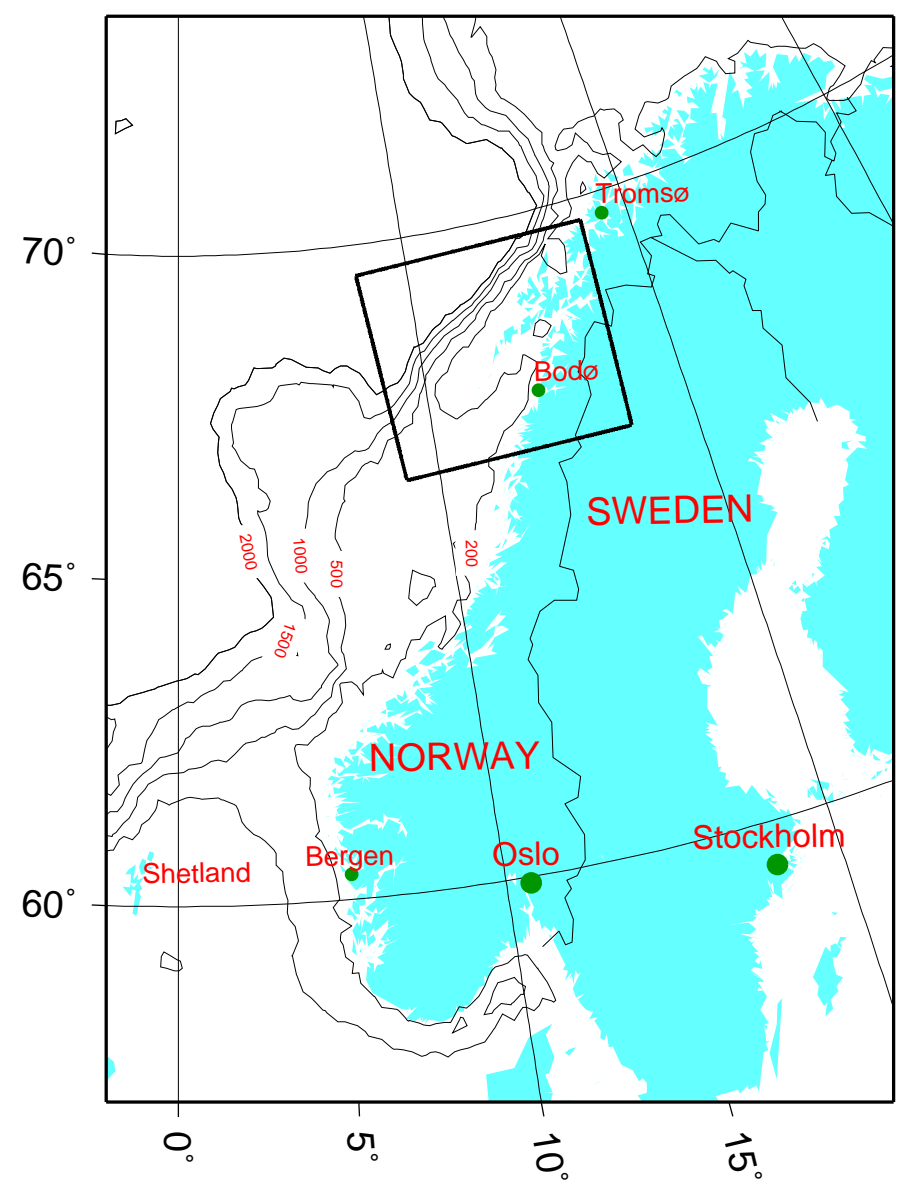

Figure 1: Map of Norwegian continental shelf with depth contours (meter) and model domain (rectangular box).

\section{Model Equations}

The depth integrated shallow water equations are formulated in flux form in a Cartesian coordinate system $(x, y, z)$ with the $\mathrm{x}$ and $\mathrm{y}$ axis in the horizontal plane and the $\mathrm{z}$ axis vertical:

$$
\begin{aligned}
& \frac{\partial U}{\partial t}+\frac{\partial}{\partial x}\left(\frac{U^{2}}{H}\right)+\frac{\partial}{\partial y}\left(\frac{U V}{H}\right)-f V=-g H \frac{\partial \eta}{\partial x}-c_{D} \frac{\sqrt{U^{2}+V^{2}}}{H} \frac{U}{H}+B_{x} \\
& \frac{\partial V}{\partial t}+\frac{\partial}{\partial x}\left(\frac{U V}{H}\right)+\frac{\partial}{\partial y}\left(\frac{V^{2}}{H}\right)+f U=-g H \frac{\partial \eta}{\partial y}-c_{D} \frac{\sqrt{U^{2}+V^{2}}}{H} \frac{V}{H}+B_{y}
\end{aligned}
$$

where $(U, V)$ are the components of volume flux vector per unit length in the horizontal plane, $\eta$ the vertical displacement of the sea surface from the mean sea level, $H=$ $H_{0}+\eta$ the total depth, $H_{0}$ the mean depth, $g$ acceleration of gravity, $f$ the Coriolis parameter, $c_{D}$ the drag coefficient of the quadratic bottom shear stress, and $\left(B_{x}, B_{y}\right)$ the components of the horizontal shear stress. In addition the continuity equation reads:

$$
\frac{\partial \eta}{\partial t}=-\frac{\partial U}{\partial x}-\frac{\partial V}{\partial y}
$$


The depth mean current velocity is defined by

$$
\bar{u}=\frac{U}{H}, \quad \bar{v}=\frac{V}{H}
$$

In this model domain the direct effect of the tide generating forces is negligible, and the tidal motion is mainly driven by the boundary input i.e. sea surface elevation and volume fluxes. In the present problem these equations span a wide parameter range from weak tidal flows on the deeper part of the shelf to strong tidal currents near The Lofoten Islands. We introduce a velocity scale $u_{s}$, a time scale $t_{s}$ corresponding to half the tidal period, a tidal amplitude $a$, a length scale for the spatial variation of the tidal flow $l_{s}$ and a depth scale $h_{s}$. With this scaling we can define the tidal excursion $l_{t}=u_{s} t_{s}$ and the equations (1)-(2) can be recast into dimensionless form:

$$
\begin{aligned}
& \frac{\partial U}{\partial t}+\alpha\left[\frac{\partial}{\partial x}\left(\frac{U^{2}}{H}\right)+\frac{\partial}{\partial y}\left(\frac{U V}{H}\right)\right]-\delta V=-\beta H \frac{\partial \eta}{\partial x}-\gamma \frac{\sqrt{U^{2}+V^{2}}}{H} \frac{U}{H} \\
& \frac{\partial V}{\partial t}+\alpha\left[\frac{\partial}{\partial x}\left(\frac{U V}{H}\right)+\frac{\partial}{\partial y}\left(\frac{V^{2}}{H}\right)\right]+\delta U=-\beta H \frac{\partial \eta}{\partial y}-\gamma \frac{\sqrt{U^{2}+V^{2}}}{H} \frac{V}{H}
\end{aligned}
$$

with $B_{x}=B_{y}=0$. The dimensionless form of the continuity equation reads:

$$
\frac{\epsilon}{\alpha} \frac{\partial \eta}{\partial t}=-\frac{\partial U}{\partial x}-\frac{\partial V}{\partial y}
$$

with $H=H_{0}+\epsilon \eta$. The same symbols are here tacitly used for the dimensionless variables $U, V, H$ and $\eta$ as in the dimensional equations (1)-(3). The dimensionless parameters are defined by:

$$
\alpha=\frac{l_{t}}{l_{s}}, \quad \beta=\frac{g a}{u_{s}^{2}} \frac{l_{t}}{l_{s}}, \quad \gamma=\frac{c_{D} l_{t}}{h_{s}}, \quad \delta=f t_{s}, \quad \epsilon=\frac{a}{h_{s}}
$$

Here $\alpha$, and $\epsilon$ are measures of the importance of the convective terms and the nonlinear surface elevation terms respectively. The parameters $\beta, \gamma$, and $\delta$ scale pressure, bottom friction and rotational effects respectively. In deep water $\alpha, \epsilon$ and $\gamma \ll 1$ and the equations reduces to the linearized shallow water equation with negligible bottom friction. Near the coast, with strong tidal currents, $\alpha, \beta, \gamma$ are of $O(1)$ and all terms in the equation of motion have to be retained. In not too shallow water $\epsilon \ll 1$ the left hand side of equation (3) may be neglected rendering a nearly non-divergent volume flux as long as $\alpha$ is of $O(1)$.

In this paper we have tested the performance of a linear tidal model and made the approximations $\alpha=\epsilon=0$ and $\epsilon / \alpha$ of $O(1)$. The equations are then discretized on a Cgrid (Mesinger and Arakawa 1976) with a semi-implicit numerical scheme. This scheme is widely used for depth integrated ocean models. A discussion of its dispersion and stability properties is given e.g. by Martinsen et al. (1979) and Gjevik and Straume (1989). The stability criteria expressed by the numerical time step $\Delta t$ is:

$$
\Delta t \leq \frac{\Delta x}{2 \sqrt{2 g H_{\max }}}
$$

where $\Delta x$ is the grid size and $H_{\max }$ is the maximum depth in the model domain. 


\section{Model set up and boundary conditions}

The depth matrix was evaluated on an UTM coordinate grid with $\Delta x=0.5 \mathrm{~km}$ resolution. Near the coast average depths for each grid box were read from Norwegian coastal charts most of them with scale 1 : 50000. Outside the zone covered by the coastal charts depths are from a bathymetric data base with $500 \mathrm{~m}$ spatial resolution provided by the Norwegian Hydrographic Service (NHS) or interpolated from a $4 \times$ $4 \mathrm{~km}$ digital data base. The main part of the model domain is covered by the UTM zone $33 \mathrm{~W}$, which we for convenience have extended west of $12^{\circ} \mathrm{E}$ into UTM zone $32 \mathrm{~W}$. The resulting depth matrix of $810 \times 725$ grid points is depicted in figure 2 . The Lofoten Islands stretch in northeastern direction from Røst towards Lødingen (map code 5, table 1). North of The Lofoten Islands, Vesterålen is located between Stokmarknes and Andenes. The wide fjord south of the Lofoten chain of islands, from Røst and Bodø eastward to Lødingen, is Vestfjorden. The general topography with a relatively wide shelf south of Lofoten and a narrow shelf west of Vesterålen and Andenes is clearly revealed by this map.

Boundary conditions for the model were obtained by interpolating surface elevation and volume fluxes from a large scale model of the Norwegian and the Barents Sea with $25 \mathrm{~km}$ grid resolution (Gjevik et al. 1990;1994). The interior solution was adjusted to the specified boundary conditions with the flow relaxation scheme (FRS), Martinsen and Engedahl (1987). The FRS softens the transition from an exterior solution (here the interpolated data) to an interior solution (model area) by use of a grid zone where the two solutions dominate at each ends respectively. The width of the FRS zone is here taken to be ten grid cells.

Two types of boundary forcing (exterior solutions) has been tested; i) only surface elevation specified and ii) both surface and and volume fluxes specified. Single or selected combinations of the tidal components $M_{2}, S_{2}, N_{2}$ and $K_{1}$ are used in the conditions i) and ii). The total simulation times are 85 hours when only semi-diurnal components are included and 96 hours if the diurnal component is present. At $t=0$ the boundary forcing is applied from rest at the oceanic sides of the model domain and the amplitudes grow according to $(1-\exp (-\sigma t))$. We have used $\sigma=4.6 \cdot 10^{-5} \mathrm{~s}^{-1}$ which implies full effect of boundary conditions after about 12 hours.

The simulations are started from rest i.e. the internal solution $U=V=\eta=0$. When the simulation has reached 72 hours full fields (all grid points) for current and elevation are stored with half an hour sampling. Time series recorded from $t=0$ at 45 stations within the model domain are examined to ensure that a steady state oscillation is reached. The surface elevation attained steady state rapidly in all stations, but for some stations time series for currents included noise due to the transient start. Longer simulations have been performed but for the results presented in this report 72 hours was sufficient to reach an acceptable steady state. Harmonic analysis is then performed on the full fields to determine the amplitude and phase for the appropriate tidal component. The simulations have normally been performed with a bottom friction coefficient of $c_{D}=0.003$, but simulations are also done with $c_{D}=0$ in order to investigate the effect of bottom friction. Generally, without bottom friction the simulations will need longer time to reach an acceptable steady state and bottom friction seems to be of minor importance regarding the modelled sea level. If not explicitly mentioned the results presented are from simulations with bottom friction included, single component forcing and boundary condition i). 


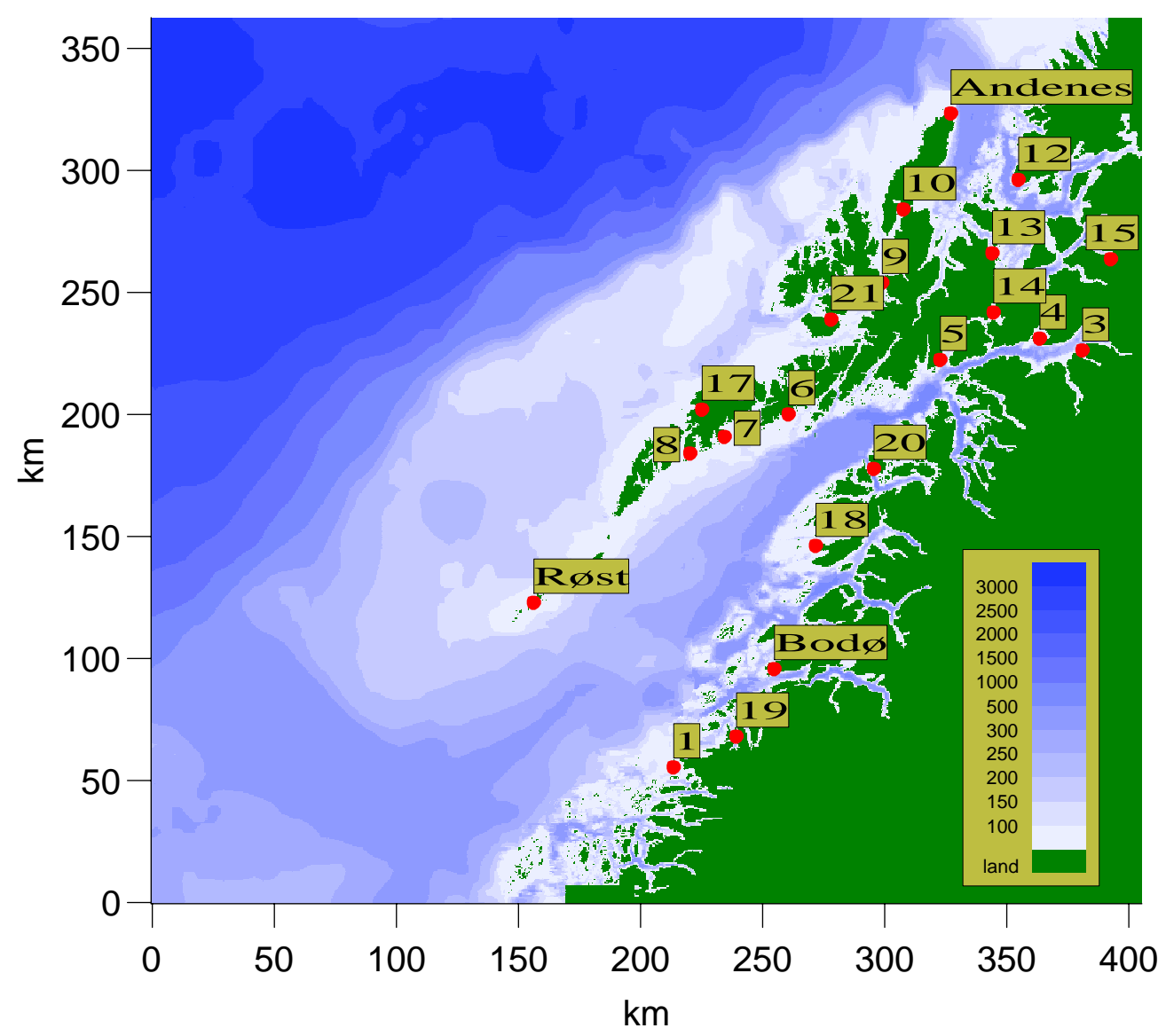

Figure 2: Model domain with $0.5 \mathrm{~km}$ grid resolution. Color depth-scale in meters. The position of the tidal stations, table 1, are marked with (red) dots and appropriate map codes.

\section{Results}

The calculated harmonic constants for sea level amplitude, $h_{n}$, and phase relative Greenwich, $g_{n}$, are compared with observations from 21 stations (table 1 and figure 2). For Bodø, Narvik, Lødingen, Kabelvåg, Risøyhamna, Andenes, Harstad and Evenskjær (primary stations) the harmonic constants are evaluated from long time series of observed sea level (Norwegian Hydrographic Service 1998). For the other stations in table 1 (secondary stations) harmonic constants are calculated from shorter time series, typically 2-4 weeks. NHS has given us access to this data set, which previously has not been used for validation of tidal models. For the secondary stations NHS has also calculated correction factors for amplitude and time of high and low water relative to nearest primary station. By using these correction factors we have also deduced a set of derived harmonic constants for the secondary stations. Harmonic constants are listed in the tables 2-5 for both primary and secondary stations.

Current fields from the model are compared with observations in four locations: the Moskenes sound, the Gimsøy channel, the Tjeldsund channel and the Sortland channel. NHS has provided measurements of the tidal current in the areas around Gimsøy (G1G2) and Sortland (S1-S5) and the University of Bergen the data for the stations in The Moskenes sound (L1-L4), figure 11 section 4.2. Where measurements from several depths were available we used the mean value for comparison with model current data from the nearest grid point. 
Table 1: List of tidal stations.

\begin{tabular}{|l|c|c|}
\hline Station & Coordinates & Map Code \\
\hline Støtt & $66^{\circ} 55^{\prime} N, 13^{\circ} 27^{\prime} E$ & 1 \\
\hline Bod $\varnothing$ & $67^{\circ} 17^{\prime} N, 14^{\circ} 23^{\prime} E$ & Bod $(2)$ \\
\hline Narvik & $68^{\circ} 26^{\prime} N, 17^{\circ} 25^{\prime} E$ & 3 \\
\hline Bogen & $68^{\circ} 29^{\prime} N, 17^{\circ} 00^{\prime} E$ & 4 \\
\hline Lødingen & $68^{\circ} 25^{\prime} N, 16^{\circ} 00^{\prime} E$ & 5 \\
\hline Kabelvåg & $68^{\circ} 13^{\prime} N, 14^{\circ} 30^{\prime} E$ & 6 \\
\hline Stamsund & $68^{\circ} 08^{\prime} N, 13^{\circ} 52^{\prime} E$ & 7 \\
\hline Ballstad & $68^{\circ} 04^{\prime} N, 13^{\circ} 32^{\prime} E$ & 8 \\
\hline Sortland & $68^{\circ} 42^{\prime} N, 15^{\circ} 26^{\prime} E$ & 9 \\
\hline Risøyhamna & $68^{\circ} 58^{\prime} N, 15^{\circ} 39^{\prime} E$ & 10 \\
\hline Andenes & $69^{\circ} 19^{\prime} N, 16^{\circ} 09^{\prime} E$ & Andenes $(11)$ \\
\hline Skrolsvik & $69^{\circ} 04^{\prime} N, 16^{\circ} 50^{\prime} E$ & 12 \\
\hline Harstad & $68^{\circ} 48^{\prime} N, 16^{\circ} 33^{\prime} E$ & 13 \\
\hline Evenskjær & $68^{\circ} 35^{\prime} N, 16^{\circ} 33^{\prime} E$ & 14 \\
\hline Røkenes & $68^{\circ} 46^{\prime} N, 17^{\circ} 45^{\prime} E$ & 15 \\
\hline Røst & $67^{\circ} 30^{\prime} N, 12^{\circ} 04^{\prime} E$ & Røst $(16)$ \\
\hline Tangstad & $68^{\circ} 13^{\prime} N, 13^{\circ} 38^{\prime} E$ & 17 \\
\hline Helnessund & $67^{\circ} 44^{\prime} N, 14^{\circ} 46^{\prime} E$ & 18 \\
\hline Inndyr & $67^{\circ} 02^{\prime} N, 14^{\circ} 02^{\prime} E$ & 19 \\
\hline Skutvik & $68^{\circ} 01^{\prime} N, 15^{\circ} 20^{\prime} E$ & 20 \\
\hline Stokmarknes & $68^{\circ} 33^{\prime} N, 14^{\circ} 54^{\prime} E$ & 21 \\
\hline
\end{tabular}

\subsection{Sea level, semi-diurnal and diurnal components}

\subsubsection{The $M_{2}$ component}

Contour lines for the $M_{2}$ sea level amplitude and phase are depicted in figure 3 . The phase lines are approximately perpendicular to the shelf slope with gradually increasing phases north-east ward, showing that the $M_{2}$ wave component propagates basically in a north-easterly direction. Separation between phase lines are also larger north of The Lofoten Islands, where the shelf is narrow, which imply a larger propagation speed than south of Lofoten where the shelf is wider.

The $60 \mathrm{~cm}$ amplitude isoline follows the shelf slope and relatively low amplitudes are found in Vesterålen north of The Lofoten Islands where the shelf is narrow. South of Lofoten there is almost a linear increase in amplitude from the shelf edge towards the coast. The convergence of contour lines for the amplitude at Røst and The Lofoten Point is due to the scattering of the northward propagating wave by the Lofoten chain of islands. Due to the constraints of the coast line there is also an increase in amplitude by about $24 \mathrm{~cm}$ from the mouth of Vestfjorden near Røst eastward towards Narvik (map code 3 ) at the head of the fjord. Across the Lofoten chain of islands there is a difference in amplitude of 15-30 $\mathrm{cm}$ which drives the strong tidal currents in the channels between the islands. The general variation in amplitude and phase seen here is also reproduced to a large extend by an idealized model with a corresponding transition from a broad 


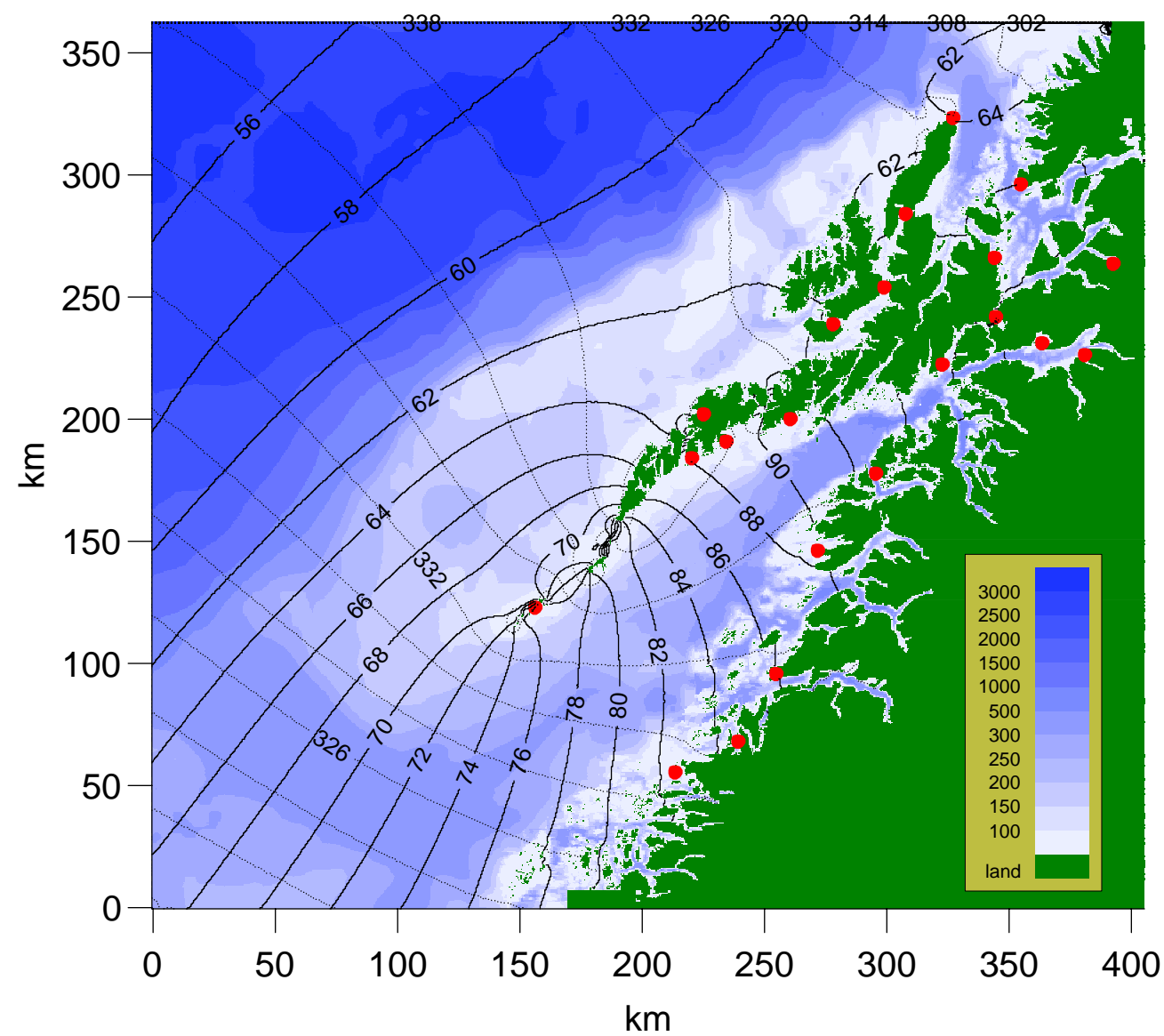

Figure 3: $M_{2}$ sea surface elevation. Isolines for amplitude (solid lines, 2-cm separation) and phase (broken lines, 2-degree separation). Tidal stations (table 1) marked by (red) dots. Shading shows depth with scale in legend (meter). Boundary forcing: only surface elevation.
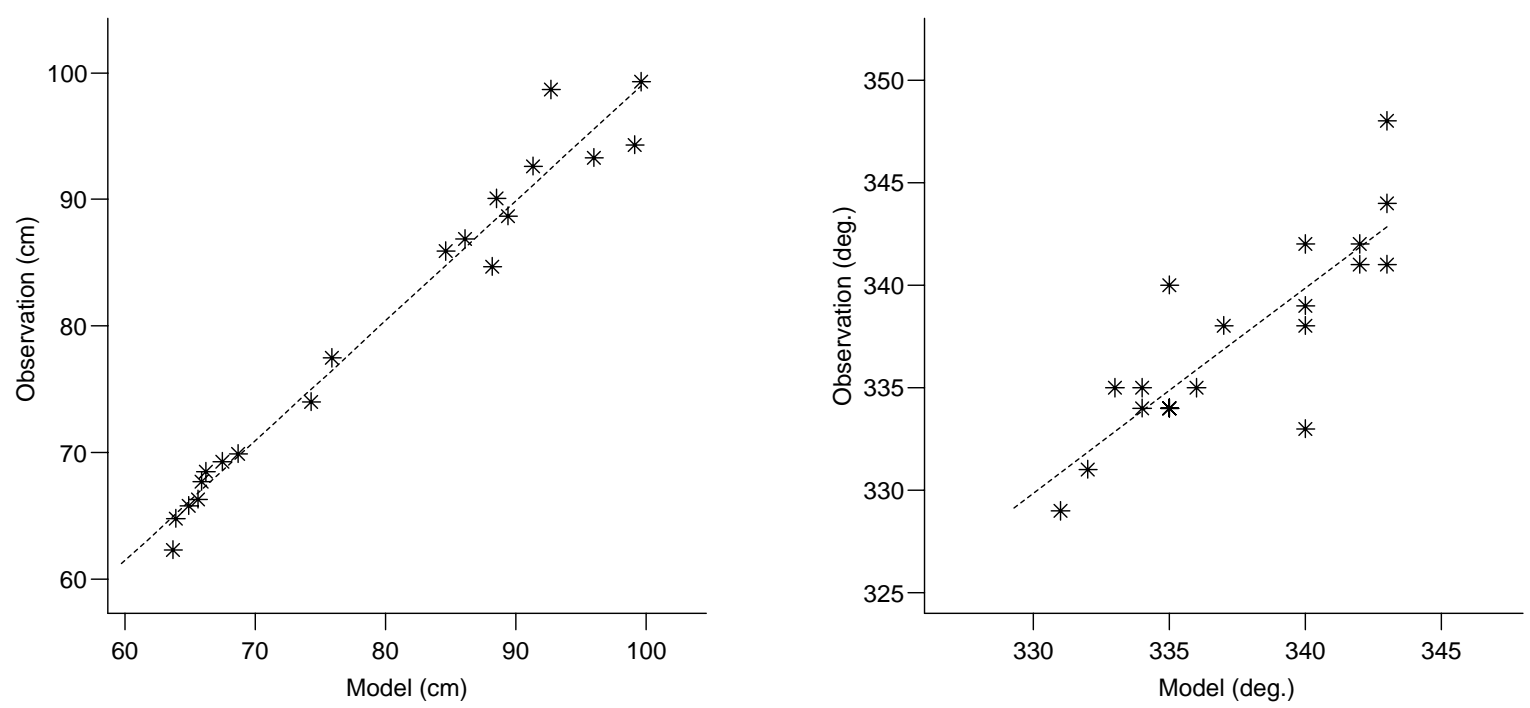

Figure 4: Scattering diagrams $M_{2}$. Comparison between modelled and observed amplitude (left panel) and phase (right panel). The least squares regression line (dashed). The standard deviation estimate between model and observation is $2.29 \mathrm{~cm}$ (amplitude) and 2.54 degrees (phase). Boundary forcing: only surface elevation. 
to a narrow shelf (Ommundsen and Gjevik 2000).

By comparing amplitudes and phases with observations, table 2 and figure 4 , the best fit is found for the run with prescribed surface elevation at the open boundaries with a standard deviation of only $2.3 \mathrm{~cm}$ for amplitude and 2.5 degrees for phase. To obtain this good agreement we have made minor adjustments of the surface elevation at the open boundaries. This indicates that further improvements can be made by using more advanced optimization techniques, e.g. Lardner (1993). For the run with surface elevation and fluxes prescribed at the open boundaries the corresponding standard deviations are $3.8 \mathrm{~cm}$ and 5.9 degrees.

Table 2: Observed and modelled amplitude $\left(h_{n} \mathrm{~cm}\right)$ and phase $\left(g_{n}\right.$ degree, GMT) of the $M_{2}$ tide. Model results with prescribed elevation at the open boundaries (Elevation) and elevation and fluxes at the open boundaries (Elev. \& flux).

\begin{tabular}{|l|r|r|r|r|r|r|r|r|}
\hline \multirow{2}{*}{ Station } & \multicolumn{2}{|c|}{ Observed } & \multicolumn{2}{c|}{ Derived } & \multicolumn{2}{c|}{$\begin{array}{c}\text { Model } \\
\text { Elevation }\end{array}$} & \multicolumn{2}{c|}{\begin{tabular}{c} 
Modev. \& flux \\
\cline { 2 - 10 }
\end{tabular}} \\
\cline { 2 - 10 } & $h_{n}$ & $g_{n}$ & $h_{n}$ & $g_{n}$ & $h_{n}$ & $g_{n}$ & $h_{n}$ & $g_{n}$ \\
\hline Støtt & & & 86.0 & 326 & 82.5 & 329 & 84.8 & 324 \\
\hline Bod $\varnothing$ & 86.9 & 331 & & & 86.1 & 332 & 88.5 & 327 \\
\hline Narvik & 99.3 & 334 & & & 99.6 & 335 & 102.2 & 330 \\
\hline Bogen & 94.3 & 340 & 99.1 & 343 & 99.1 & 335 & 101.7 & 330 \\
\hline Lødingen & 93.3 & 334 & & & 96.0 & 335 & 98.6 & 330 \\
\hline Kabelvåg & 92.6 & 334 & & & 91.3 & 335 & 93.8 & 330 \\
\hline Stamsund & 88.7 & 335 & 91.2 & 336 & 89.4 & 336 & 91.9 & 331 \\
\hline Ballstad & 84.7 & 338 & 87.8 & 335 & 88.2 & 337 & 90.7 & 332 \\
\hline Sortland & 66.3 & 342 & 66.9 & 337 & 65.6 & 340 & 69.3 & 335 \\
\hline Risøyhamna & 67.7 & 342 & & & 65.9 & 342 & 70.3 & 336 \\
\hline Andenes & 64.8 & 341 & & & 63.9 & 342 & 69.2 & 336 \\
\hline Skrolsvik & 68.5 & 341 & 67.1 & 344 & 66.2 & 343 & 71.7 & 337 \\
\hline Harstad & 69.3 & 344 & & & 67.5 & 343 & 73.2 & 336 \\
\hline Evenskjær & 74.0 & 333 & & & 74.3 & 340 & 79.7 & 334 \\
\hline Røkenes & 69.9 & 348 & 64.6 & 348 & 68.7 & 343 & 74.4 & 337 \\
\hline Røst & 77.5 & 334 & & 332 & 75.9 & 334 & 78.1 & 329 \\
\hline Tangstad & 62.3 & 339 & 65.2 & 336 & 63.7 & 340 & 66.7 & 334 \\
\hline Helnessund & 90.1 & 335 & & & 88.5 & 333 & 91.0 & 328 \\
\hline Inndyr & 85.9 & 329 & & & 84.6 & 331 & 87.0 & 325 \\
\hline Skutvik & 98.7 & 335 & & & 92.7 & 334 & 95.3 & 329 \\
\hline Stokmarknes & 65.8 & 338 & & 339 & 64.9 & 340 & 68.4 & 335 \\
\hline
\end{tabular}




\subsubsection{The $S_{2}$ component}

The amplitude of the $S_{2}$ component is about one third of the $M_{2}$ and the general features of the variation of the amplitude and phase are similar (figure 5). The standard deviations between modelled and observed amplitude and phase are $2.8 \mathrm{~cm}$ and 5.3 degrees respectively for the $S_{2}$ simulations with surface elevation prescribed at the open boundary, table 3 and figure 6 .

Table 3: Observed and modelled amplitude $\left(h_{n} \mathrm{~cm}\right)$ and phase $\left(g_{n}\right.$ degree, GMT) of the $S_{2}$ tide. Model results with prescribed elevation at the open boundaries (Elevation).

\begin{tabular}{|c|c|c|c|c|c|c|}
\hline \multirow[t]{2}{*}{ Station } & \multicolumn{2}{|c|}{ Observed } & \multicolumn{2}{|c|}{ Derived } & \multicolumn{2}{|c|}{$\begin{array}{c}\text { Model } \\
\text { Elevation }\end{array}$} \\
\hline & $h_{n}$ & $g_{n}$ & $h_{n}$ & $g_{n}$ & $h_{n}$ & $g_{n}$ \\
\hline Støtt & & & 29.7 & 4 & 27.2 & $\overline{3}$ \\
\hline Bod $\varnothing$ & 30.5 & 9 & & & 28.5 & 6 \\
\hline Narvik & 35.3 & 13 & & & 33.1 & 10 \\
\hline Bogen & 38.2 & 21 & 34.8 & 21 & 32.9 & 10 \\
\hline Lødingen & 32.2 & 11 & & & 31.8 & 10 \\
\hline Kabelvåg & 32.6 & 13 & & & 30.2 & 10 \\
\hline Stamsund & 32.3 & 12 & 32.0 & 14 & 29.6 & 11 \\
\hline Ballstad & 35.2 & 15 & 30.8 & 13 & 29.1 & 11 \\
\hline Sortland & 24.4 & 21 & 23.5 & 16 & 23.0 & 17 \\
\hline Risøyhamna & 21.1 & 22 & & & 23.2 & 18 \\
\hline Andenes & 22.0 & 20 & & & 22.5 & 18 \\
\hline Skrolsvik & 23.2 & 21 & 22.1 & 24 & 23.3 & 20 \\
\hline Harstad & 23.8 & 23 & & & 23.8 & 18 \\
\hline Evenskjær & 26.1 & 11 & & & 26.2 & 15 \\
\hline Røkenes & 22.1 & 16 & 21.3 & 29 & 24.3 & 19 \\
\hline Røst & 27.6 & 13 & & 10 & 25.2 & 9 \\
\hline Tangstad & 24.8 & 18 & 22.9 & 14 & 22.2 & 16 \\
\hline Helnessund & 32.5 & 15 & & & 29.2 & 8 \\
\hline Inndyr & 30.2 & 8 & & & 27.9 & 5 \\
\hline Skutvik & 36.3 & 24 & & & 30.7 & 9 \\
\hline Stokmarknes & 22.1 & 15 & & 18 & 22.9 & 17 \\
\hline
\end{tabular}




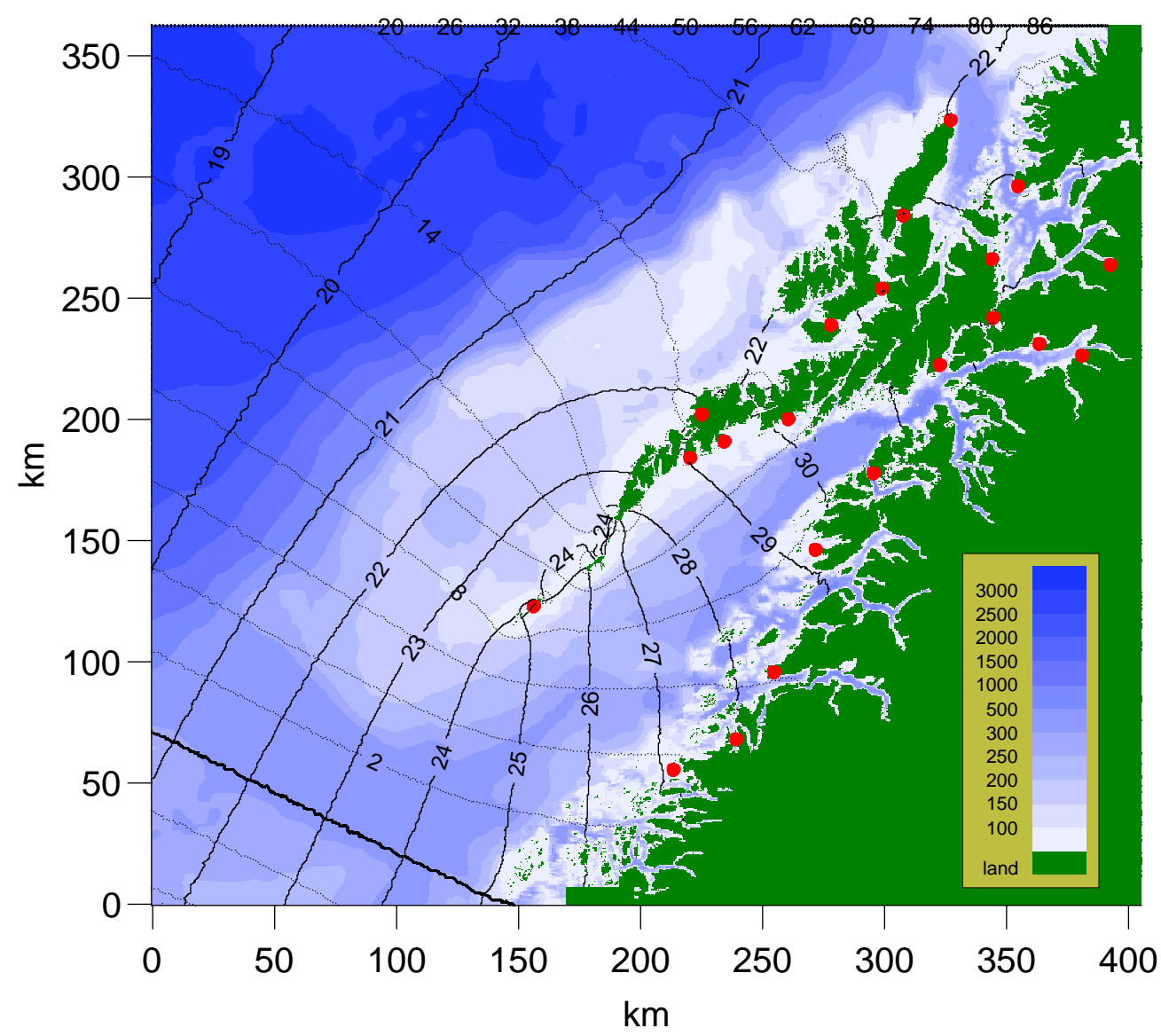

Figure 5: $S_{2}$ sea surface elevation. Isolines for amplitude (solid lines, 1-cm separation) and phase (broken lines, 2-degree separation). Tidal stations (table 1) marked by (red) dots. Shading shows depth with scale in legend (meter).
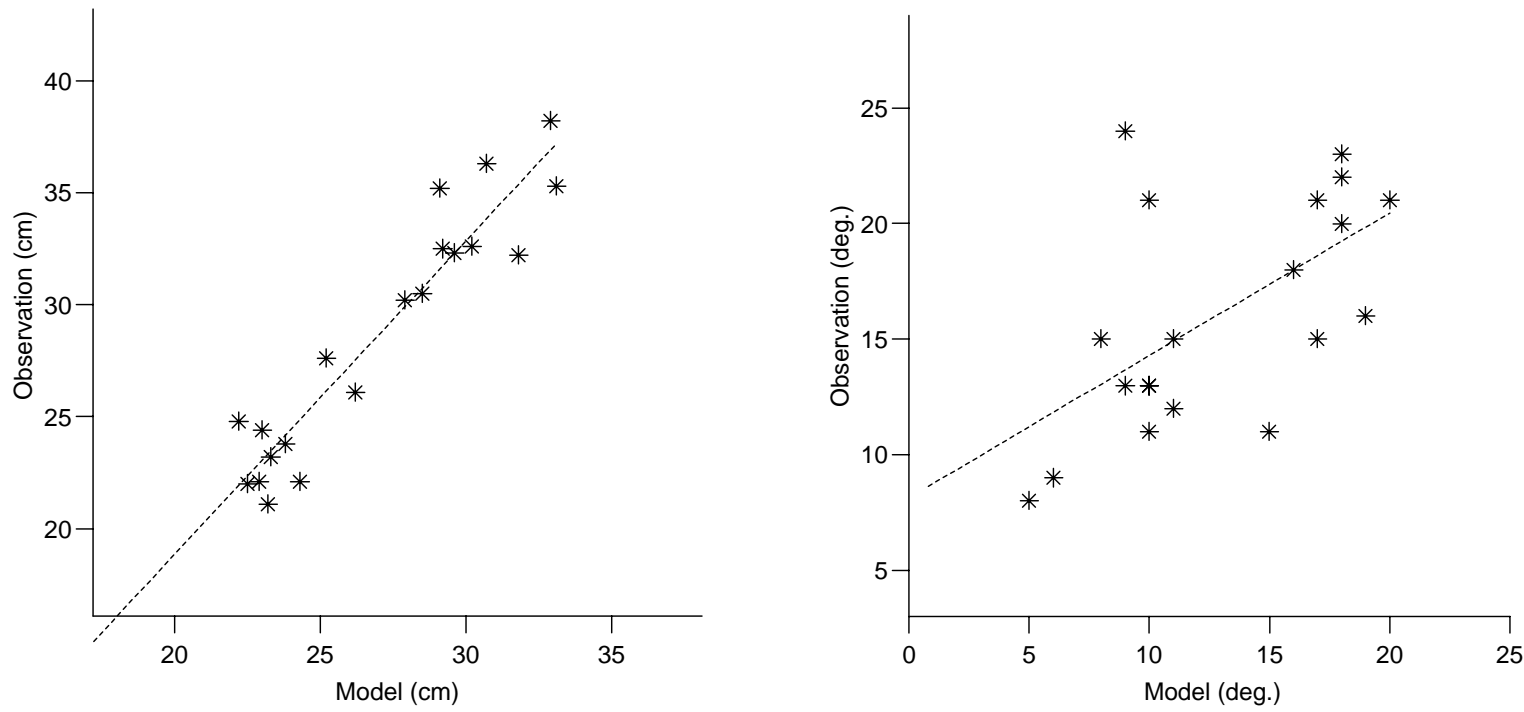

Figure 6: Scattering diagrams $S_{2}$. Comparison between modelled and observed amplitude (left panel) and phase (right panel). The least squares regression line (dashed). The standard deviation estimate between model and observation is $2.8 \mathrm{~cm}$ (amplitude) and 5.3 degrees (phase). 


\subsubsection{The $N_{2}$ component}

The amplitude of the $N_{2}$ component is about one fifth of the $M_{2}$ and the general features of the variation of the amplitude and phase are similar (figure 7 ). The standard deviations between modelled and observed amplitude and phase are $1.5 \mathrm{~cm}$ and 9.5 degrees respectively for the $N_{2}$ simulations with surface elevation prescribed at the open boundary, table 4 and figure 8 .

Table 4: Observed and modelled amplitude $\left(h_{n} \mathrm{~cm}\right)$ and phase $\left(g_{n}\right.$ degree, GMT) of the $\mathrm{N}_{2}$ tide. Model results with prescribed elevation at the open boundaries (Elevation).

\begin{tabular}{|l|r|r|r|r|r|r|}
\hline \multirow{2}{*}{ Station } & \multicolumn{2}{|c|}{ Observed } & \multicolumn{2}{c|}{ Derived } & \multicolumn{2}{c|}{$\begin{array}{c}\text { Model } \\
\text { Elevation }\end{array}$} \\
\cline { 2 - 7 } & $h_{n}$ & $g_{n}$ & $h_{n}$ & $g_{n}$ & $h_{n}$ & $g_{n}$ \\
\hline Støtt & & & 17.5 & 303 & 17.5 & 310 \\
\hline Bodø & 17.7 & 307 & & & 18.3 & 313 \\
\hline Narvik & 20.3 & 311 & & & 21.1 & 316 \\
\hline Bogen & & & 20.2 & 318 & 21.0 & 316 \\
\hline Lødingen & 20.3 & 314 & & & 20.4 & 316 \\
\hline Kabelvåg & 18.9 & 311 & & & 19.4 & 317 \\
\hline Stamsund & & & 18.6 & 311 & 19.0 & 317 \\
\hline Ballstad & & & 17.9 & 310 & 18.8 & 318 \\
\hline Sortland & 12.7 & 343 & 13.6 & 313 & 15.4 & 321 \\
\hline Risøyhamna & 16.9 & 326 & & & 15.4 & 323 \\
\hline Andenes & 13.2 & 317 & & & 15.1 & 323 \\
\hline Skrolsvik & 14.3 & 315 & 13.6 & 321 & 15.6 & 324 \\
\hline Harstad & 14.2 & 320 & & & 15.9 & 323 \\
\hline Evenskjær & 15.1 & 310 & & & 17.3 & 321 \\
\hline Røkenes & & & 13.1 & 325 & 16.2 & 324 \\
\hline Røst & 16.2 & 310 & & 308 & 16.3 & 315 \\
\hline Tangstad & & & 13.3 & 311 & 14.8 & 320 \\
\hline Helnessund & 17.7 & 315 & & & 18.8 & 314 \\
\hline Inndyr & 17.6 & 304 & & & 17.9 & 312 \\
\hline Skutvik & & & & & 19.7 & 316 \\
\hline Stokmarknes & 12.6 & 339 & & 315 & 15.1 & 321 \\
\hline
\end{tabular}




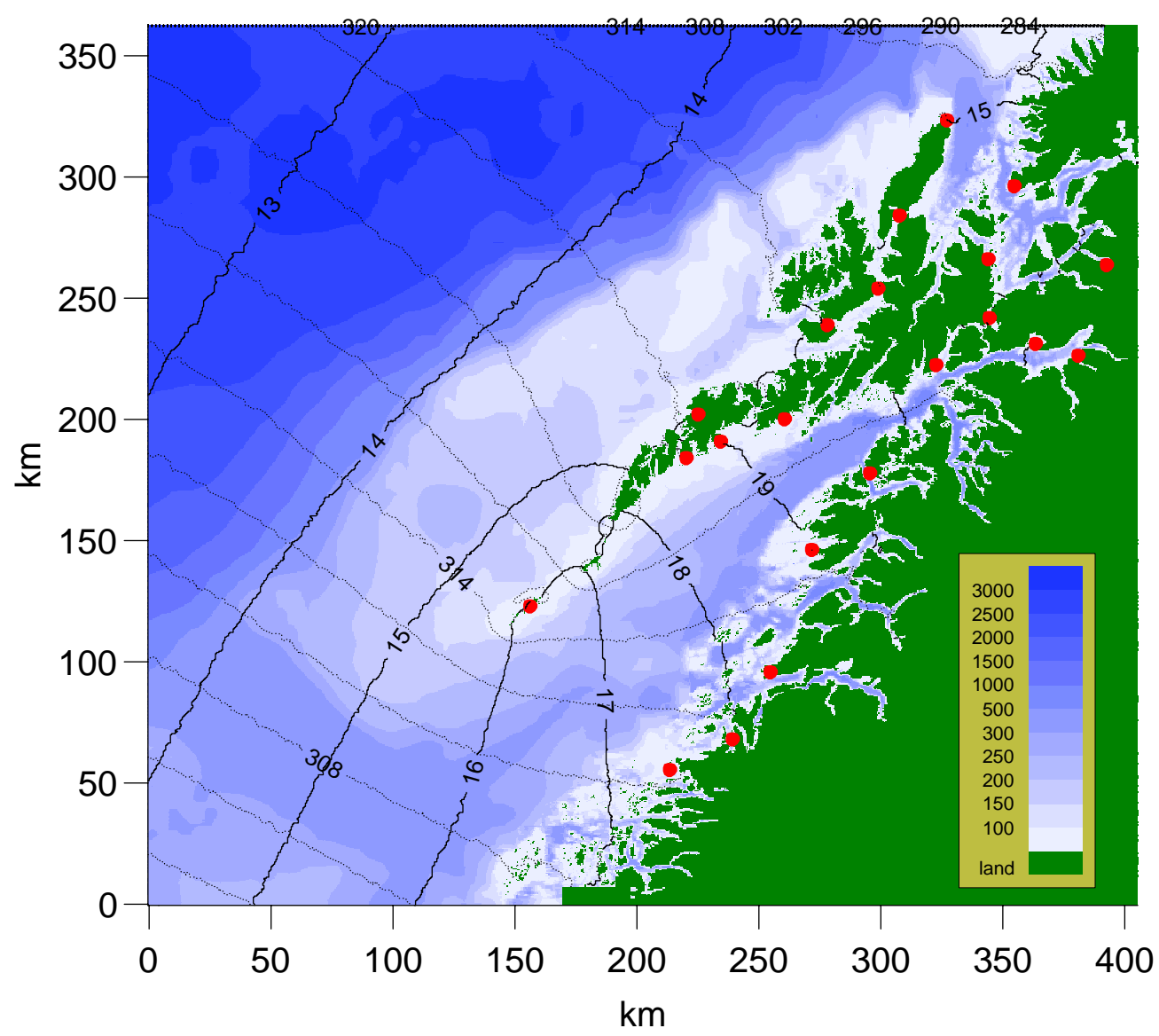

Figure 7: $N_{2}$ sea surface elevation. Isolines for equal amplitude (solid lines, 1-cm separation) and phase (broken lines, 2-degree separation). Tidal stations (table 1) marked by (red) dots. Shading shows depth with scale in legend (meter).
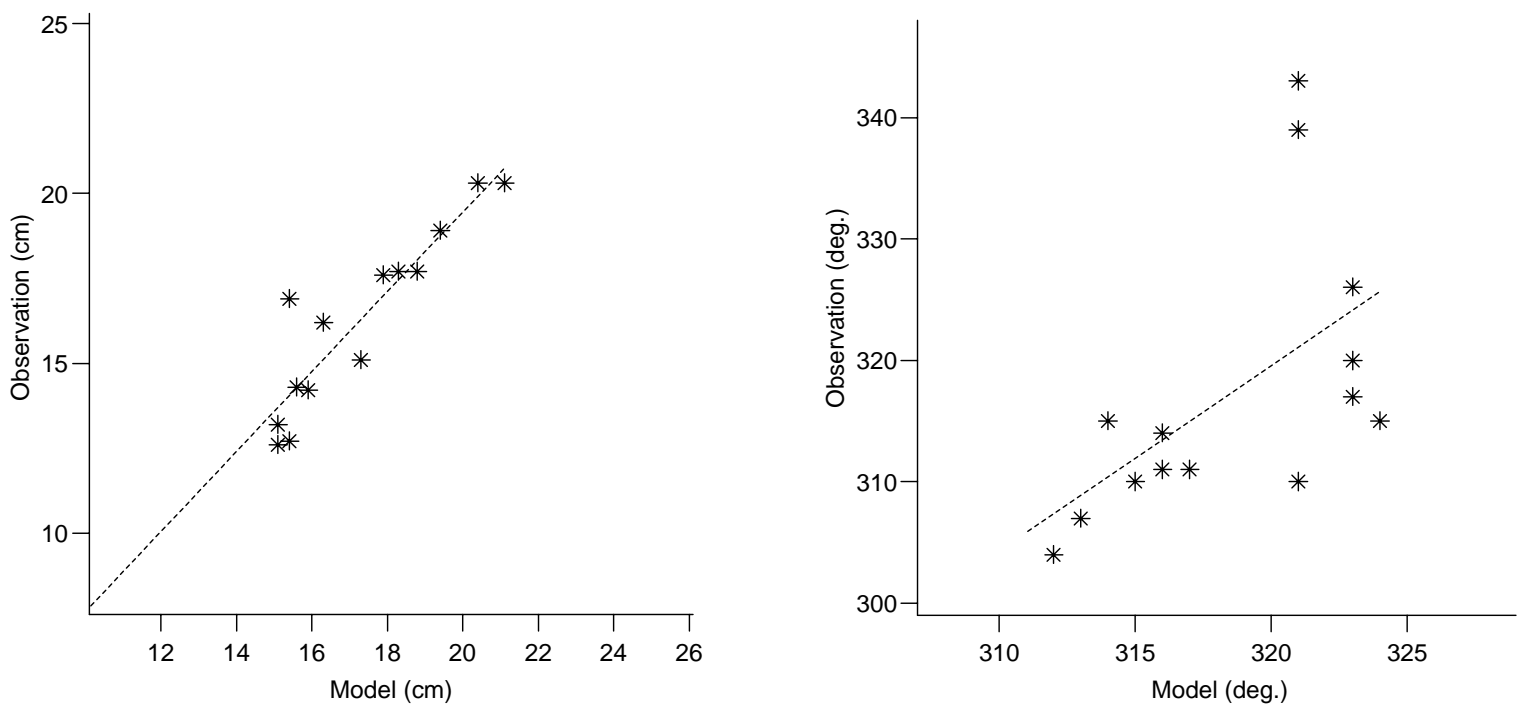

Figure 8: Scattering diagrams $N_{2}$. Comparison between modelled and observed amplitude (left panel) and phase (right panel). The least squares regression line (dashed). The standard deviation estimate between model and observation is $1.5 \mathrm{~cm}$ (amplitude) and 9.5 degrees (phase). 


\subsubsection{The $K_{1}$ component}

The amplitude of sea surface displacement for the largest diurnal component $\left(K_{1}\right)$ is about one tenth to $M_{2}$. The contour lines for amplitude and phase (figure 9) show an interesting picture with small local maxima in amplitude along the shelf slope particularly north of The Lofoten Islands where the shelf is narrow. The separation between these maxima is $25-75 \mathrm{~km}$ indicating that the diurnal tide in the area has the structure of shelf waves with short wave length.

A study of the propagation of diurnal tides by use of a model with idealized bottom topography in form of a transition from a broad to a narrow shelf shows the occurrence of shelf waves with short wave length on the narrow section of the shelf (Ommundsen and Gjevik 2000). Calculation of dispersion properties also show that the narrow shelf north of Lofoten will support shelf wave modes with diurnal period and wave lengths in the range $50-100 \mathrm{~km}$.

The regression analysis between observed and modelled amplitude and phase shows a relatively large scatter particularly for phase (figure 10). Standard deviation is 2.5 $\mathrm{cm}$ for amplitude and 16.7 degrees for phase. Clearly a more optimal set of boundary conditions is required in order to reproduce the observed amplitude and phase for $K_{1}$ with a higher degree of accuracy.

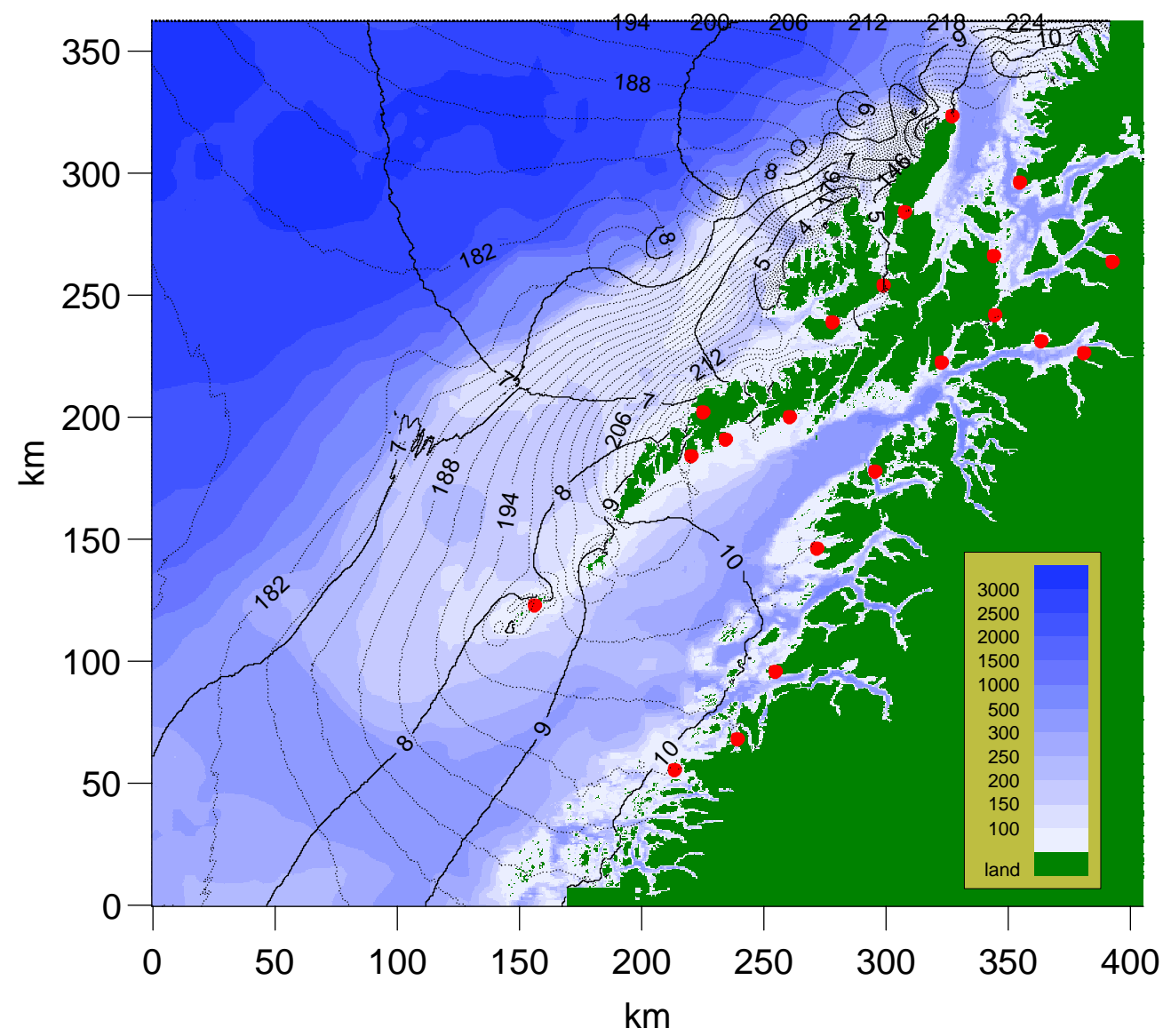

Figure 9: $K_{1}$ sea surface elevation. Isolines for amplitude (solid lines, 1-cm separation) and phase (broken lines, 2-degree separation). Tidal stations (table 1) marked by (red) dots. Shading shows depth with scale in legend (meter). 
Table 5: Observed and modelled amplitude $\left(h_{n} \mathrm{~cm}\right)$ and phase $\left(g_{n}\right.$ degree, GMT) of the $K_{1}$ tide. Model results with prescribed elevation at the open boundaries (Elevation).

\begin{tabular}{|l|r|r|r|r|r|r|}
\hline \multirow{2}{*}{ Station } & \multicolumn{2}{|c|}{ Observed } & \multicolumn{2}{c|}{ Derived } & \multicolumn{2}{c|}{$\begin{array}{c}\text { Model } \\
\text { Elevation }\end{array}$} \\
\cline { 2 - 7 } & $h_{n}$ & $g_{n}$ & $h_{n}$ & $g_{n}$ & $h_{n}$ & $g_{n}$ \\
\hline Støtt & & & 8.0 & 177 & 10.3 & 192 \\
\hline Bodø & 10.3 & 194 & & & 10.1 & 195 \\
\hline Narvik & 11.2 & 197 & & & 10.4 & 197 \\
\hline Bogen & 12.5 & 197.3 & 11.7 & 200 & 10.4 & 197 \\
\hline Lødingen & 10.2 & 197 & & & 10.3 & 197 \\
\hline Kabelvåg & 10.9 & 195 & & & 10.2 & 198 \\
\hline Stamsund & 12.0 & 194 & 10.8 & 196 & 10.2 & 197 \\
\hline Ballstad & 8.8 & 190 & 10.4 & 196 & 10.3 & 198 \\
\hline Sortland & 6.7 & 237 & 7.9 & 197 & 4.5 & 195 \\
\hline Risøyhamna & 3.2 & 213 & & & 5.9 & 157 \\
\hline Andenes & 5.3 & 184 & & & 10.4 & 178 \\
\hline Skrolsvik & 6.8 & 186 & 5.7 & 200 & 10.4 & 180 \\
\hline Harstad & 5.9 & 197 & & & 10.5 & 180 \\
\hline Evenskjær & 6.5 & 192 & & & 10.6 & 184 \\
\hline Røkenes & 7.4 & 181 & 5.5 & 202 & 10.5 & 180 \\
\hline Røst & 9.3 & 193 & & 194 & 8.5 & 194 \\
\hline Tangstad & 9.3 & 221 & 7.7 & 196 & 7.1 & 215 \\
\hline Helnessund & 11.4 & 195 & & & 10.1 & 196 \\
\hline Inndyr & 8.4 & 190 & & & 10.1 & 194 \\
\hline Skutvik & 10.3 & 187 & & & 10.3 & 197 \\
\hline Stokmarknes & 7.5 & 221 & & 198 & 5.2 & 215 \\
\hline
\end{tabular}



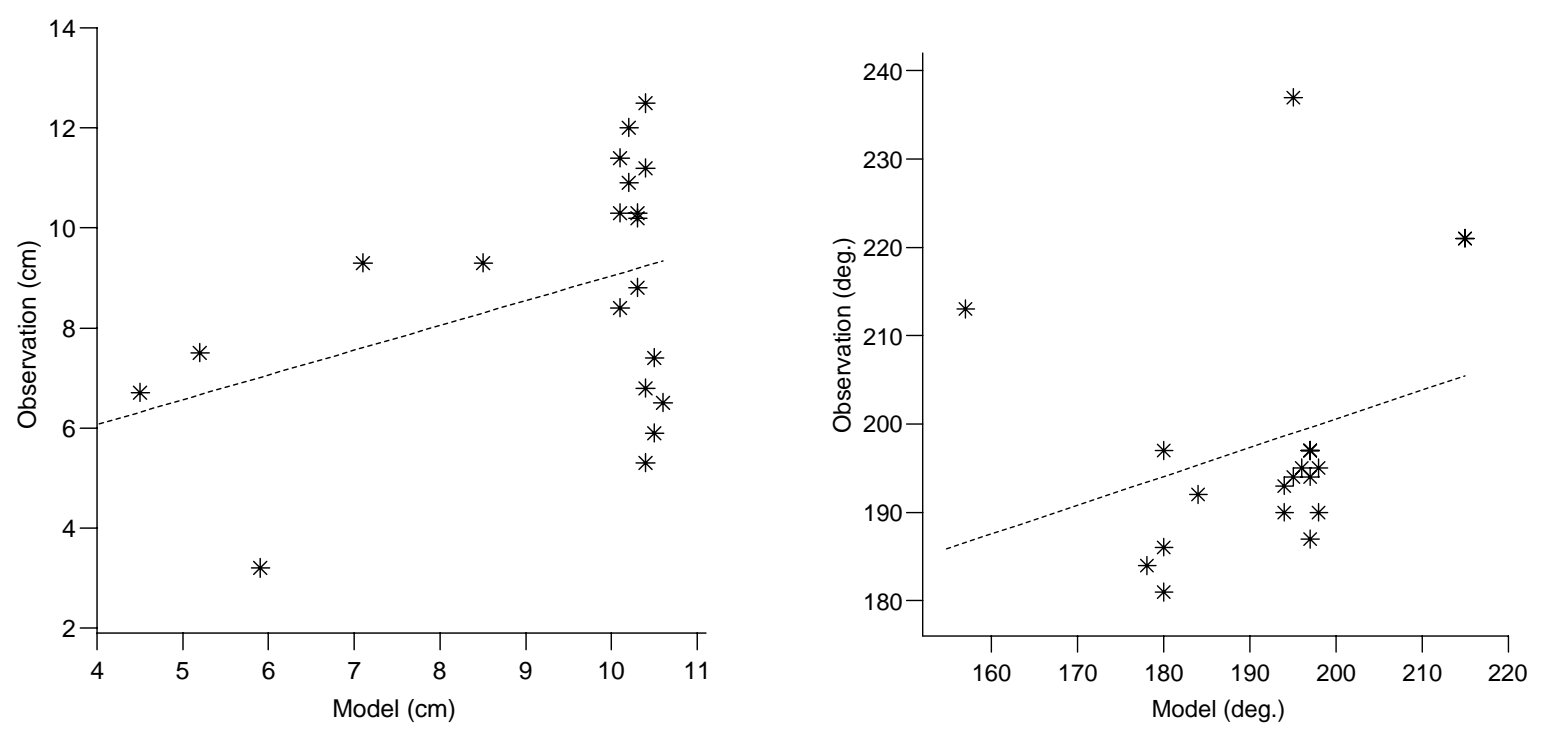

Figure 10: Scattering diagrams $K_{1}$. Comparison between modelled and observed amplitude (left panel) and phase (right panel). The least squares regression line (dashed). The standard deviation estimate between model and observation is $2.5 \mathrm{~cm}$ (amplitude) and 16.7 degrees (phase).

\subsection{Tidal currents}

\subsubsection{The Moskenes sound}

The Moskenes sound, with the small island Mosken in the middle, is located between Værøy (V) and The Lofoten Point (L), figure 12. Here runs the famous Lofoten Maelstrom known worldwide for its strength and for the mystics which surrounds it (Gjevik et al. 1997; Gjevik 1998). This strong current combined with the background current in the region is an effective mechanism in the transport of eggs, larvae etc. out of Vestfjorden (Adlandsvik and Sundby 1994; Ommundsen 1999).

In figure 12 the modelled $M_{2}$ current is depicted by its peak values and by the current ellipses. The maximum current is close to $200 \mathrm{~cm} / \mathrm{s}$. Four stations L1-L4, with measurements of the tidal current, are plotted in figure 11 and the observed and modelled parameters of the current ellipse are compared in table 6 . The observations are in good agreement with the results of our model. For station L2 the model predicts clockwise rotation while observations show counterclockwise rotation. However it should be noted that L2 is located close the borderline (figure 12) between areas of opposite rotation.

In figure 13 the current fields at the time of peak $M_{2}$ outgoing and incoming volume flux are depicted. Based on the calculated volume flux for $M_{2}$, through a cross-section area of $3.1 \cdot 10^{5} \mathrm{~m}^{2}$ between $(\mathrm{V})$ and $(\mathrm{L})$, the model predicts a mean maximum current of $116 \mathrm{~cm} / \mathrm{s}$ for the cross-section. Peak outgoing volume flux occurs about two hours after local high water in agreement with observations. 


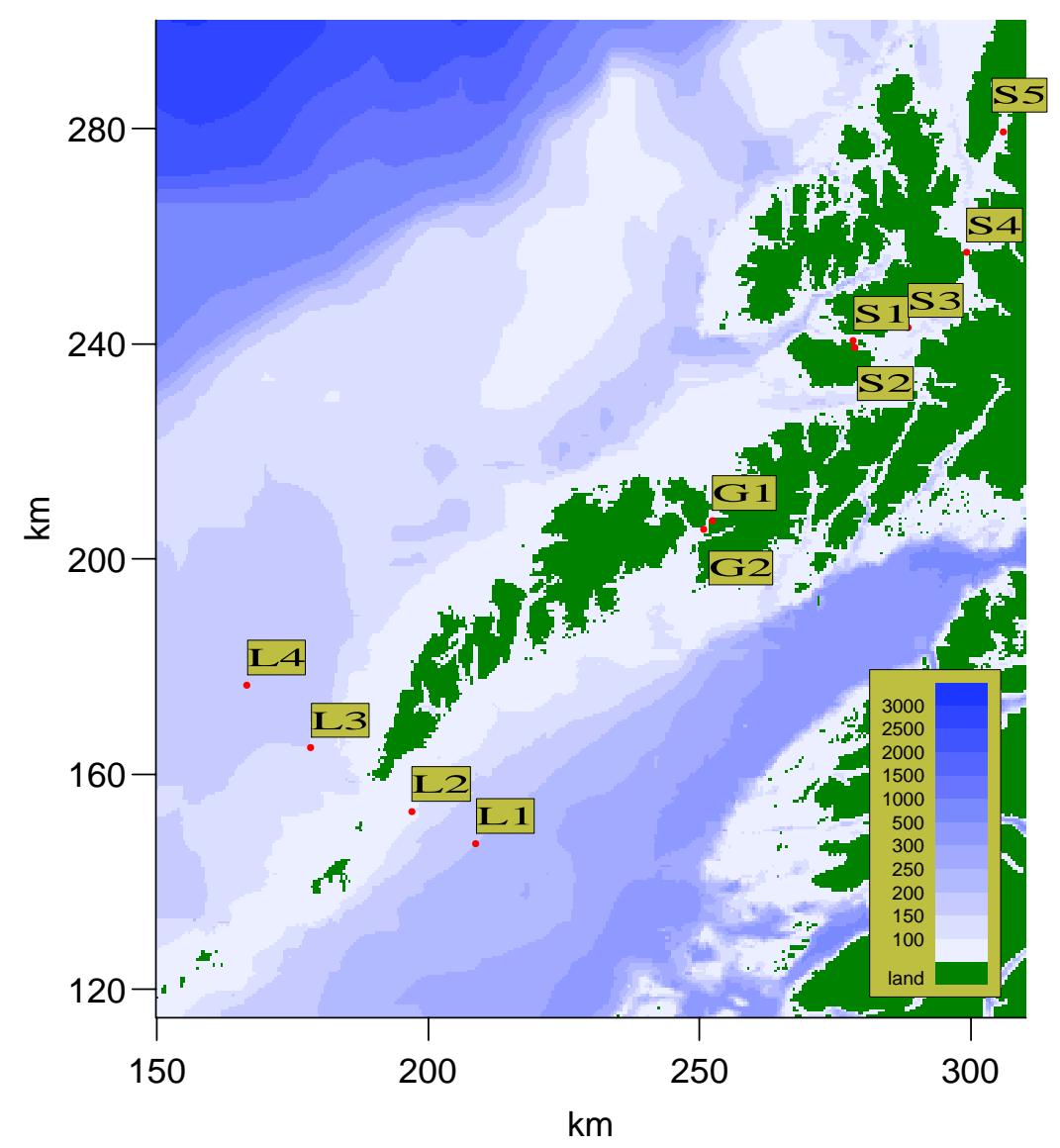

Figure 11: Location and map code for stations with measurements of tidal current. The Moskenes sound (L1-L4), the Gimsøy channel (G1-G2) and the Sortland channel (S1-S5).
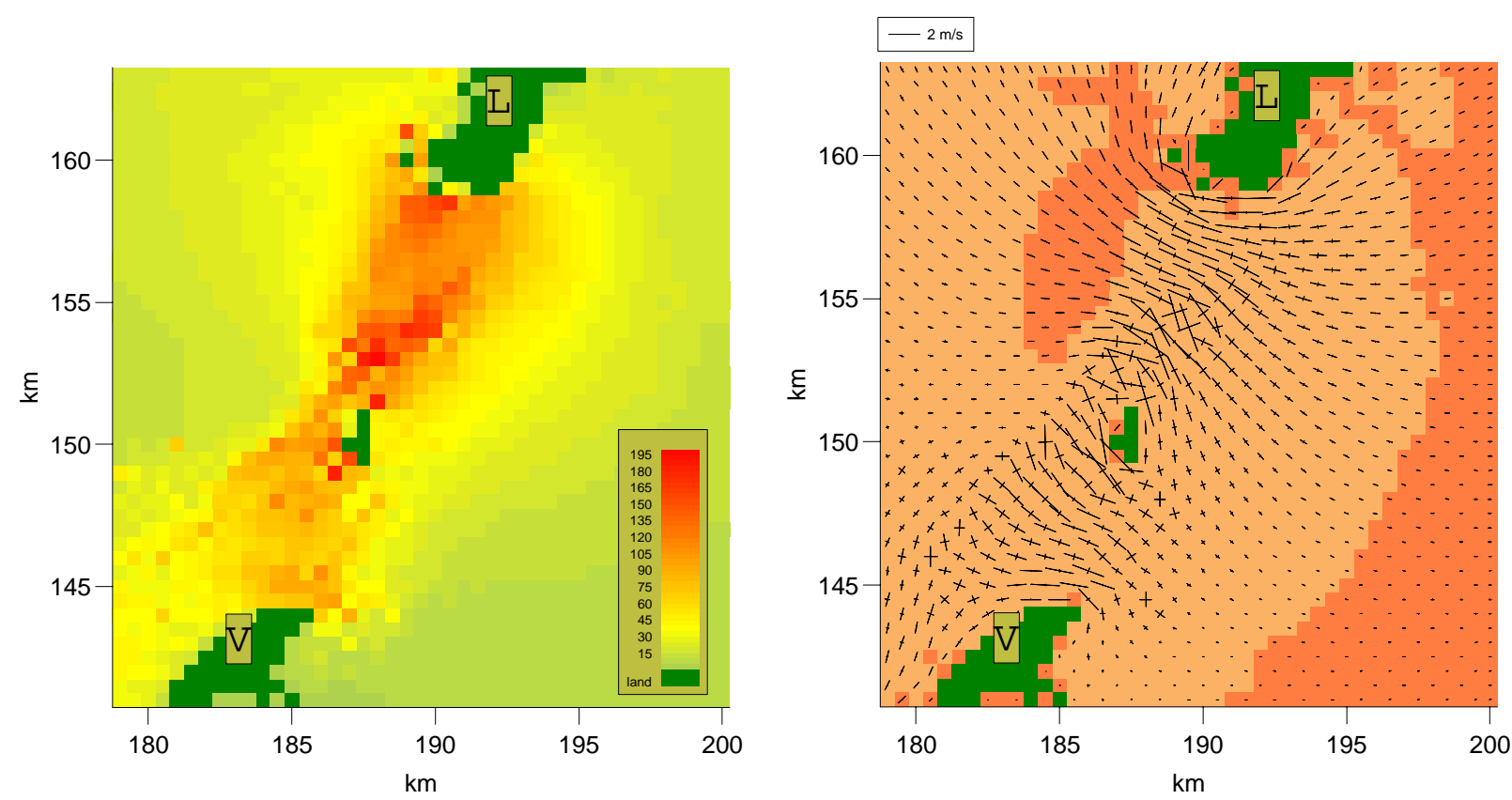

Figure 12: Left panel: Maximum $M_{2}$ current (major half axis) in the area between The Lofoten Point (L) and Værøy (V). Color scale in $\mathrm{cm} / \mathrm{s}$, legend. Right panel: Tidal ellipse and rotation of the $M_{2}$ current vector. Bright shadowing clockwise rotation, darker shadowing counterclockwise. The crosses show the major and minor axes. 

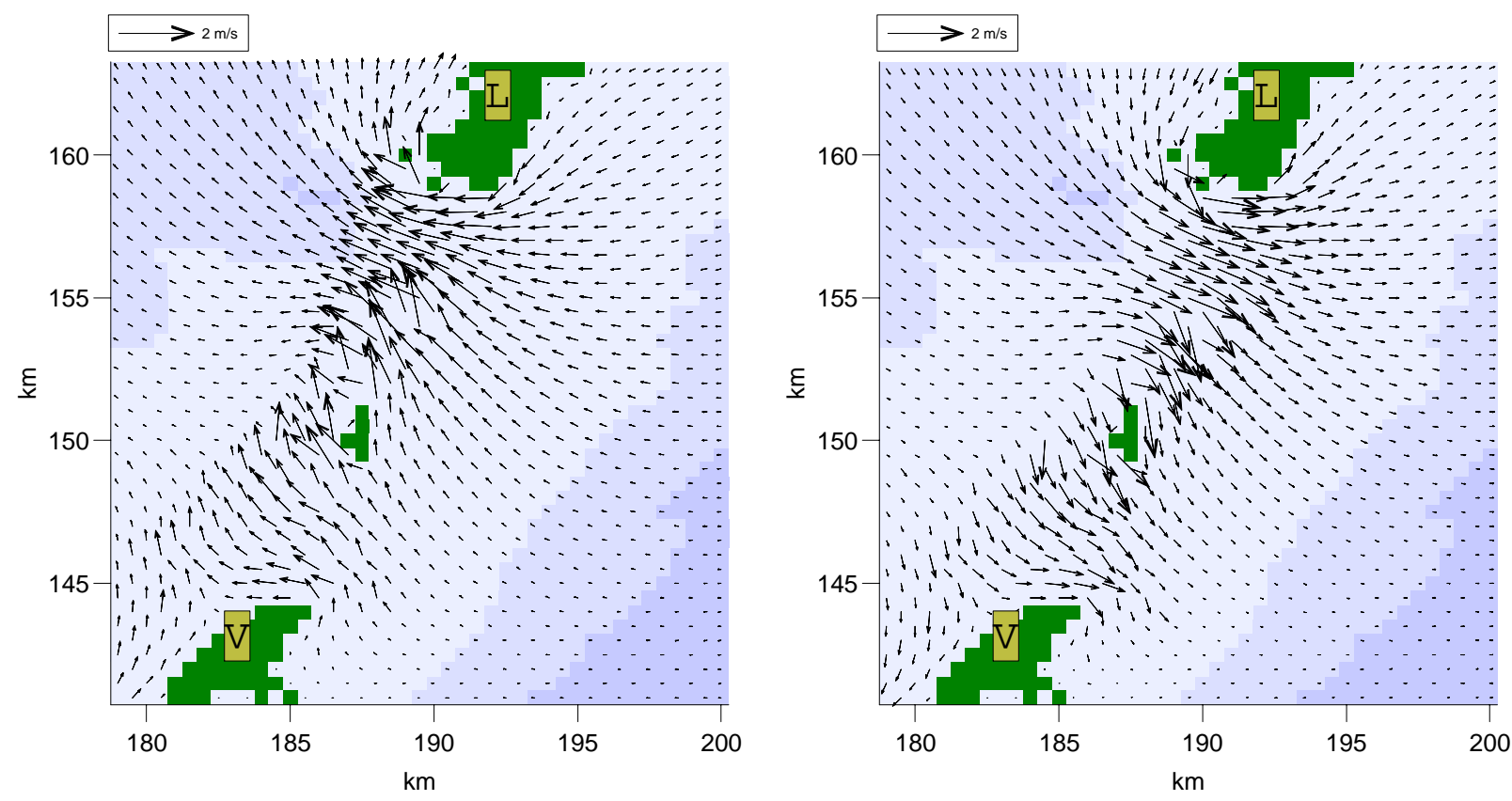

Figure 13: Left panel: $M_{2}$ current field at the time of peak outgoing volume flux between Værøy and The Lofoten Point. Right panel: $M_{2}$ current field at the time of peak incoming volume flux.

Table 6: Parameters for the $M_{2}$ current ellipse. A $(\mathrm{cm} / \mathrm{s})$, major half axis; B $(\mathrm{cm} / \mathrm{s})$, minor half axis; $\theta$ (deg.), orientation of major axis in degrees true; Rot., rotation direction for the current vector ( + , clockwise; -, counterclockwise).

\begin{tabular}{|l|r|r|r|c|r|r|r|c|}
\hline \multirow{2}{*}{$\begin{array}{l}\text { Station } \\
\text { map code) }\end{array}$} & \multicolumn{4}{|c|}{ Observed } & \multicolumn{4}{|c|}{ Model } \\
\cline { 2 - 9 } & $\mathrm{A}$ & $\mathrm{B}$ & $\theta$ & Rot. & $\mathrm{A}$ & $\mathrm{B}$ & $\theta$ & Rot. \\
\hline L1 & 9.6 & 3.1 & 64 & - & 8.1 & 1.9 & 69 & - \\
\hline L2 & 21.2 & 1.2 & 291 & - & 22.0 & 1.8 & 277 & + \\
\hline L3 & 11.6 & 4.5 & 112 & + & 15.2 & 2.0 & 155 & + \\
\hline L4 & 7.3 & 1.7 & 355 & + & 9.0 & 1.0 & 344 & + \\
\hline
\end{tabular}

\subsubsection{The Tjeldsund channel}

The Tjeldsund channel is a busy sailing route for north and south going sea traffic along the coast. For safety reasons it is important to know the current well in this area. Sandtorgstraumen, the main channel north-east of Tjeldøya, is the strongest current (coordinate $(343,240)$, figure 14). In figure 14 the modelled current is depicted by its peak values and by the current ellipses. A complex pattern is visible in the rotation of the current vector, with local strong currents in Sandtorgstraumen, Balstadstraumen (north of Tjeldøya) and Steinslandstraumen (coordinate $(346,249)$, figure 14)

According the pilot book, Norwegian Hydrographic Service (1986b), a maximum northward current in Sandtorgstraumen occurs approximately at high water running with a maximum speed of $206 \mathrm{~cm} / \mathrm{s}$ at spring. Based on the calculated volume flux for $M_{2}$ the model predicts a maximum northward current, running with $168 \mathrm{~cm} / \mathrm{s}$, approximately one hour after high water (figure 16). Correspondingly the combined 
effect of $M_{2}$ and $S_{2}$ is found to be $228 \mathrm{~cm} / \mathrm{s}$ and $M_{2}+S_{2}+N_{2}+K_{1}$ gives $314 \mathrm{~cm} / \mathrm{s}$. Figure 15 shows the current field at the time of peak $M_{2}$ volume flux in northward and southward direction respectively.
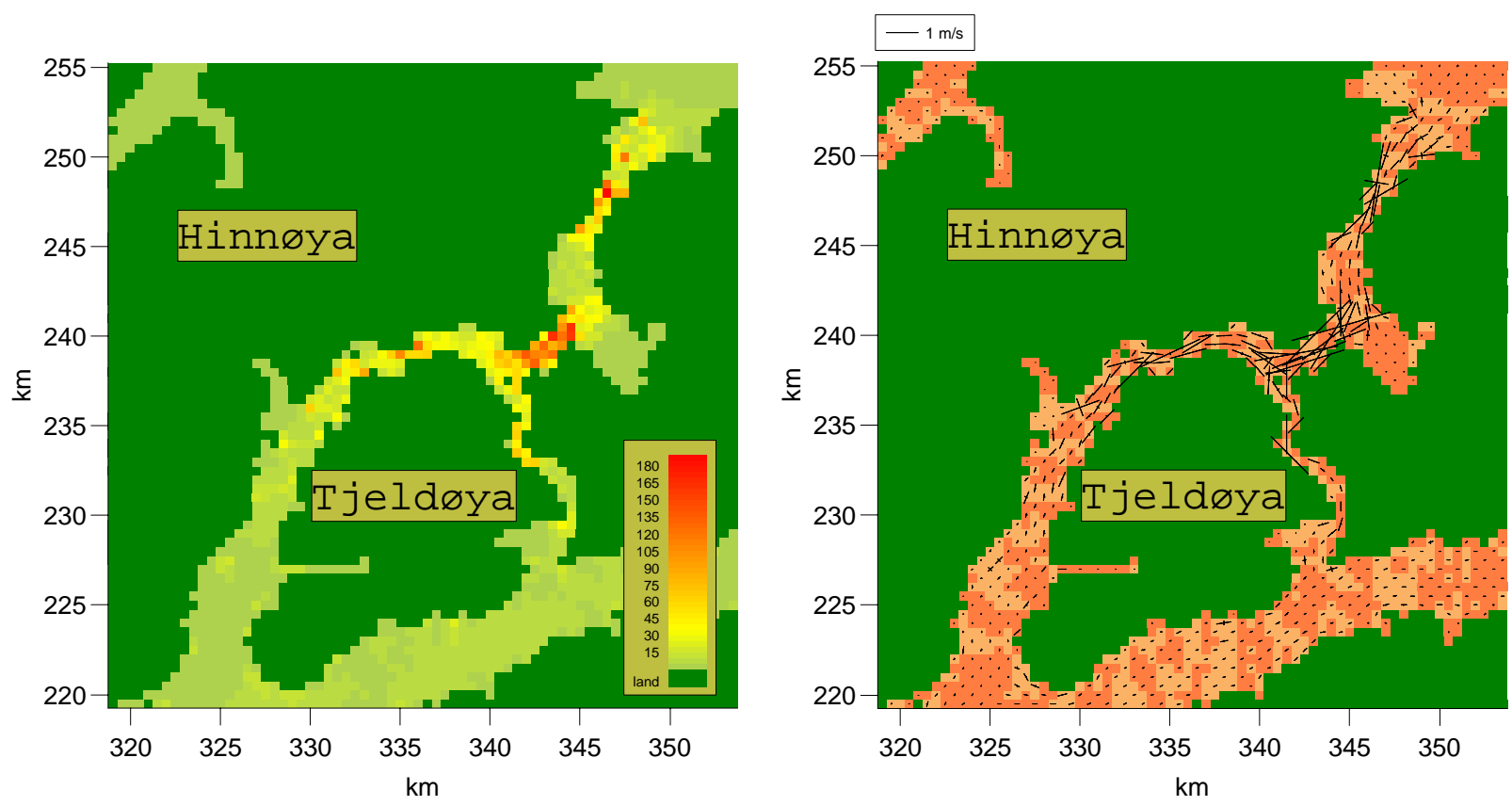

Figure 14: Left panel: Maximum $M_{2}$ current (major half axis) in the Tjelsund channel. Color scale in $\mathrm{cm} / \mathrm{s}$, legend. Right panel: Tidal ellipse and rotation of the $M_{2}$ current vector. Bright shadowing clockwise rotation, darker shadowing counterclockwise. The crosses show the major and minor axes.
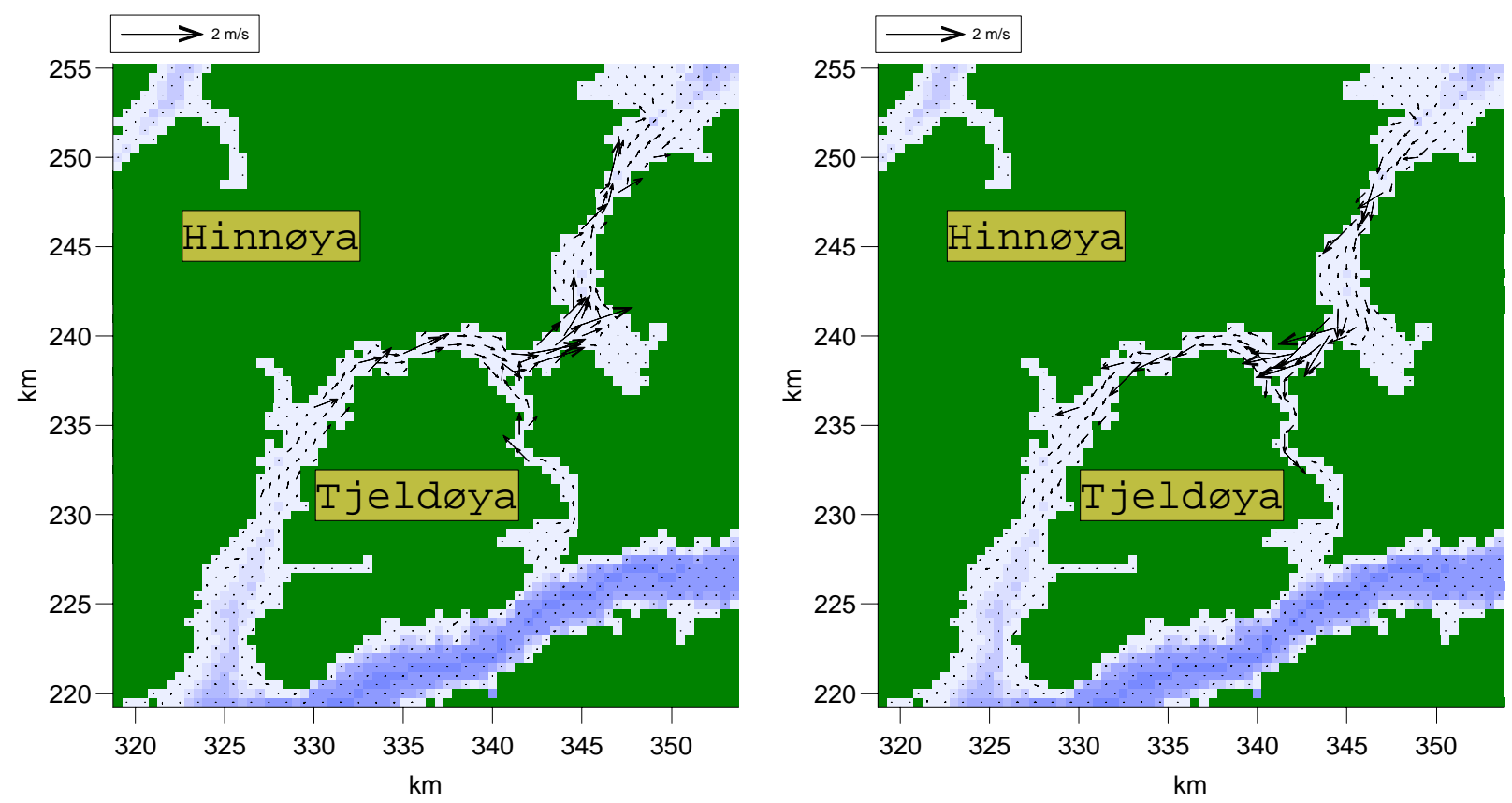

Figure 15: Left panel: Current field at the time of peak $M_{2}$ volume flux in northward direction in Sandorgstraumen between coordinates $(342,241)$ and $(345,237)$. Right panel: Current field at the time of peak $M_{2}$ volume flux in southward direction. 


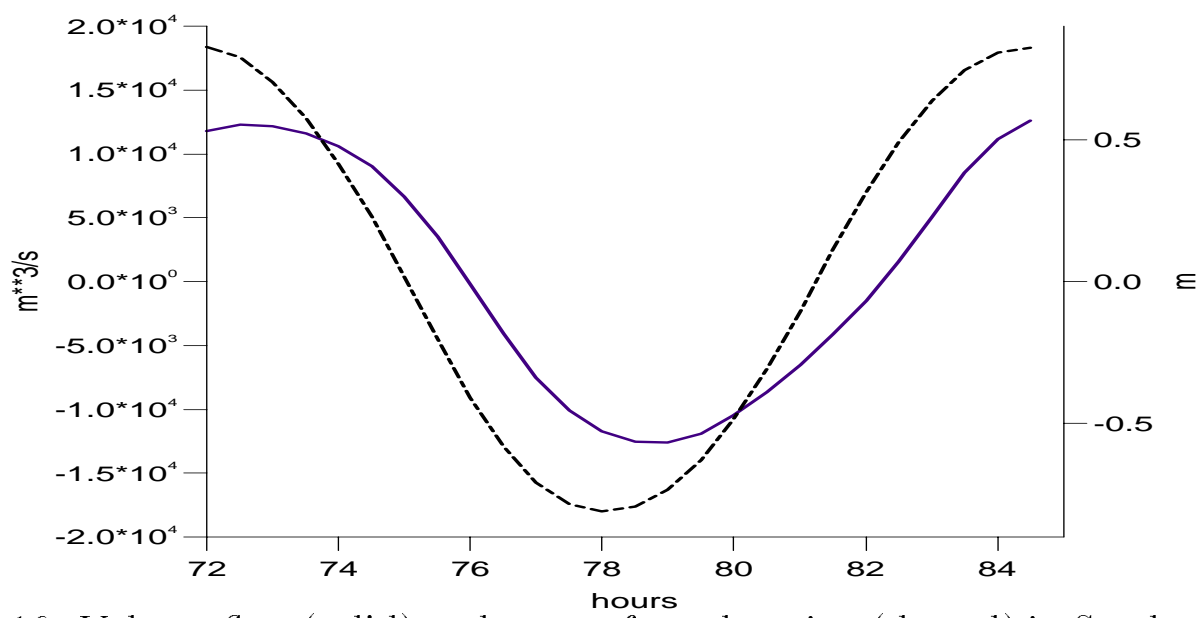

Figure 16: Volume flux (solid) and sea surface elevation (dotted) in Sandtorgstraumen, cross-section between coordinates $(342,241)$ and $(345,237)$. The total area of this crosssection is $7500 \mathrm{~m}^{2}$ leading to a mean peak northward current of $168 \mathrm{~cm} / \mathrm{s}$.

\subsubsection{The Sortland channel}

Sortlandsundet is the name of the narrow channel between Sortland and Hinnøya, figure 17. Measurements by NHS show that the current field in Sortlandsundet is characterized by a strong $K_{1}$ component. At the station S4, located in Sortlandsundet, the $K_{1}$ major half axis was measured to $48.5 \mathrm{~cm} / \mathrm{s}$ more than three times the $M_{2}$ major half axis $(13.0 \mathrm{~cm} / \mathrm{s})$, table 7 . The latter normally dominates along the Norwegian coast. The modelled current is depicted by its peak values and current ellipses for respectively the $M_{2}$ and $K_{1}$ components in figures 17 and 19 . Five stations S1-S5, with measurements of the tidal current, are plotted in figure 11 and ellipse parameters for $M_{2}$ and $K_{1}$ (station $\mathrm{S} 4$ ) are listed in table 7 . Observed and modelled current speed is in good agreement for all stations except $\mathrm{S} 2$, and captures the dominant $K_{1}$ component in station $\mathrm{S} 4$.

In figures 18 and 20 the current field at the time of peak northward and southward volume flux are shown for $M_{2}$ and $K_{1}$ respectively. The peak volume fluxes for the two components are $2888 \mathrm{~m}^{3} / \mathrm{s}$ and $12546 \mathrm{~m}^{3} / \mathrm{s}$ respectively. With a cross-section area of $26 \cdot 10^{4} \mathrm{~m}^{2}$ for Sortlandsundet the corresponding peak mean current is $11 \mathrm{~cm} / \mathrm{s}$ and 48 $\mathrm{cm} / \mathrm{s}$, which agrees well with observations.

A plot of the ratio between the major axis for $K_{1}$ and $M_{2}$ (figure 21) reveals a dominant diurnal current component on a wide area of the shelf north of Lofoten. In some cases for e.g. north of Vestvåg $\varnothing \mathrm{y}$ the $M_{2}$ current is very small leading to a large ratio although $K_{1}$ is not particularly large. The situation in Sortlandsundet seems to be unique since both the $M_{2}$ and $K_{1}$ component are relatively large. The large diurnal current in the area is clearly an effect of transformation of the diurnal tide into shelf waves along the narrow shelf north-west of Lofoten (section 4.1.4).

Lønseth and Schjølberg (1993) report a dominant diurnal current component near the shelf edge in Vesterålen (station water depth $450 \mathrm{~m}$ ) approximately located in map coordinate $(222,288)$. Measured mean values for instrument depths less than $300 \mathrm{~m}$ for the major half axes for $M_{2}$ and $K_{1}$ are $1.0 \mathrm{~cm} / \mathrm{s}$ and $2.0 \mathrm{~cm} / \mathrm{s}$ respectively. The modelled values for the major axes for $M_{2}$ and $K_{1}$ in this location are $1.1 \mathrm{~cm} / \mathrm{s}$ and $5.5 \mathrm{~cm} / \mathrm{s}$ respectively. 
Table 7: Parameters for the $M_{2}$ and $K_{1}$ (station S4) current ellipse. A $(\mathrm{cm} / \mathrm{s})$, major half axis; B (cm/s), minor half axis; $\theta$ (deg.), orientation of major axis in degrees true; Rot., rotation direction for the current vector ( + , clockwise; -, counterclockwise).

\begin{tabular}{|l|r|r|r|r|r|r|r|c|}
\hline \multirow{2}{*}{$\begin{array}{l}\text { Station } \\
\text { map code) }\end{array}$} & \multicolumn{4}{|c|}{ Observed } & \multicolumn{4}{|c|}{ Model } \\
\cline { 2 - 10 } & $\mathrm{A}$ & $\mathrm{B}$ & $\theta$ & Rot. & $\mathrm{A}$ & $\mathrm{B}$ & $\theta$ & Rot. \\
\hline S1 & 9.8 & 0.2 & 85 & - & 7.3 & 0.1 & 99 & + \\
\hline S2 & 26.9 & 0.4 & 25 & + & 9.9 & 0.1 & 316 & + \\
\hline S3 & 1.7 & 0.1 & 53 & - & 1.8 & 0.0 & 45 & + \\
\hline S4 & 13.0 & 0.3 & 10 & - & 10.2 & 0.9 & 2 & - \\
\hline S5 & 3.5 & 0.2 & 198 & - & 8.5 & 0.5 & 194 & + \\
\hline \hline S4 $\left(K_{1}\right)$ & 48.5 & 0.3 & 8 & - & 45.6 & 3.8 & 359 & - \\
\hline
\end{tabular}
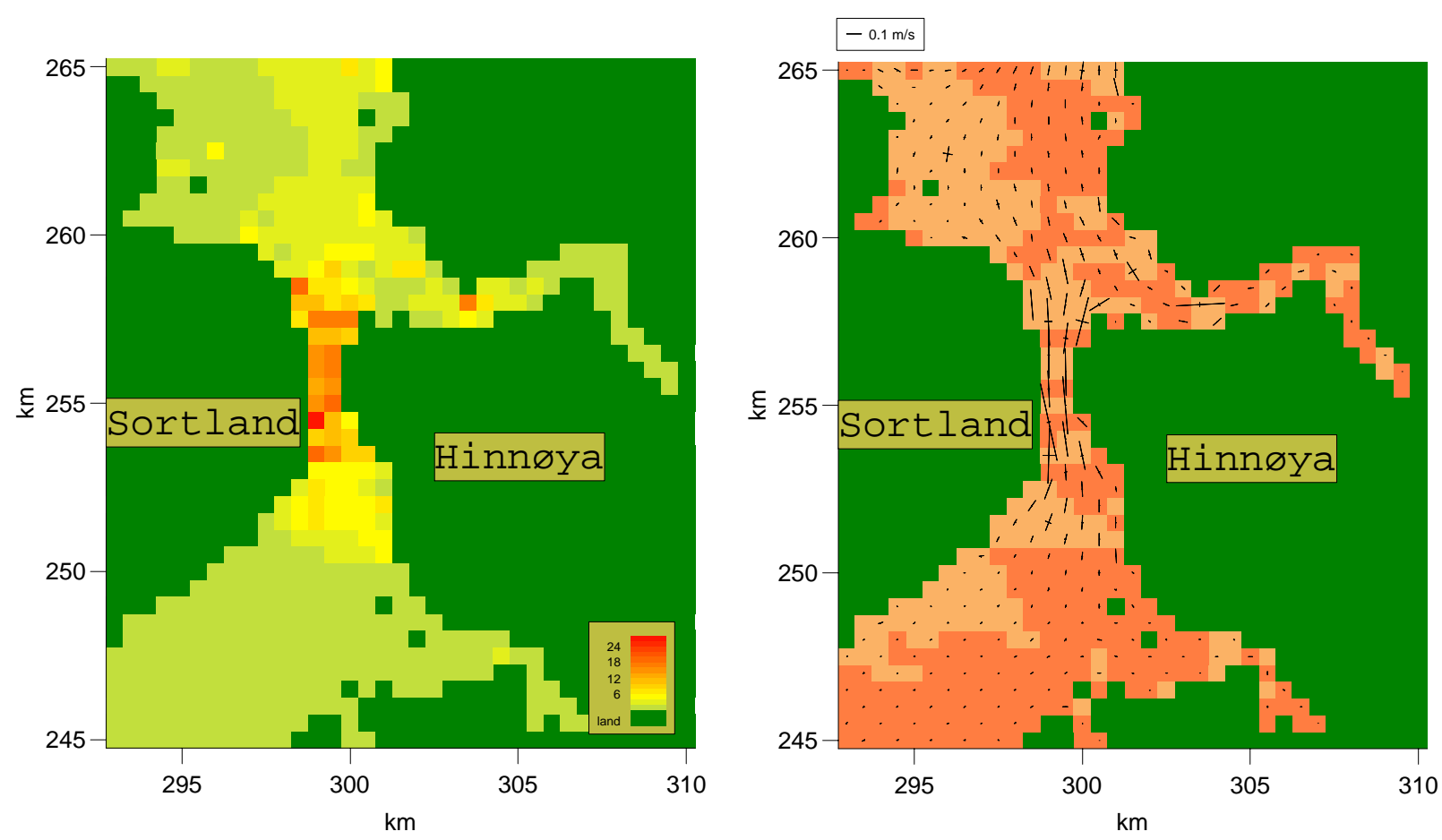

Figure 17: Left panel: Maximum $M_{2}$ current (major half axis) in Sortlandsundet between Sortland and Hinnøya. Color scale in $\mathrm{cm} / \mathrm{s}$, legend. Right panel: Tidal ellipse and rotation of the $M_{2}$ current vector. Bright shadowing clockwise rotation, darker shadowing counterclockwise. The crosses show the major and minor axes. 

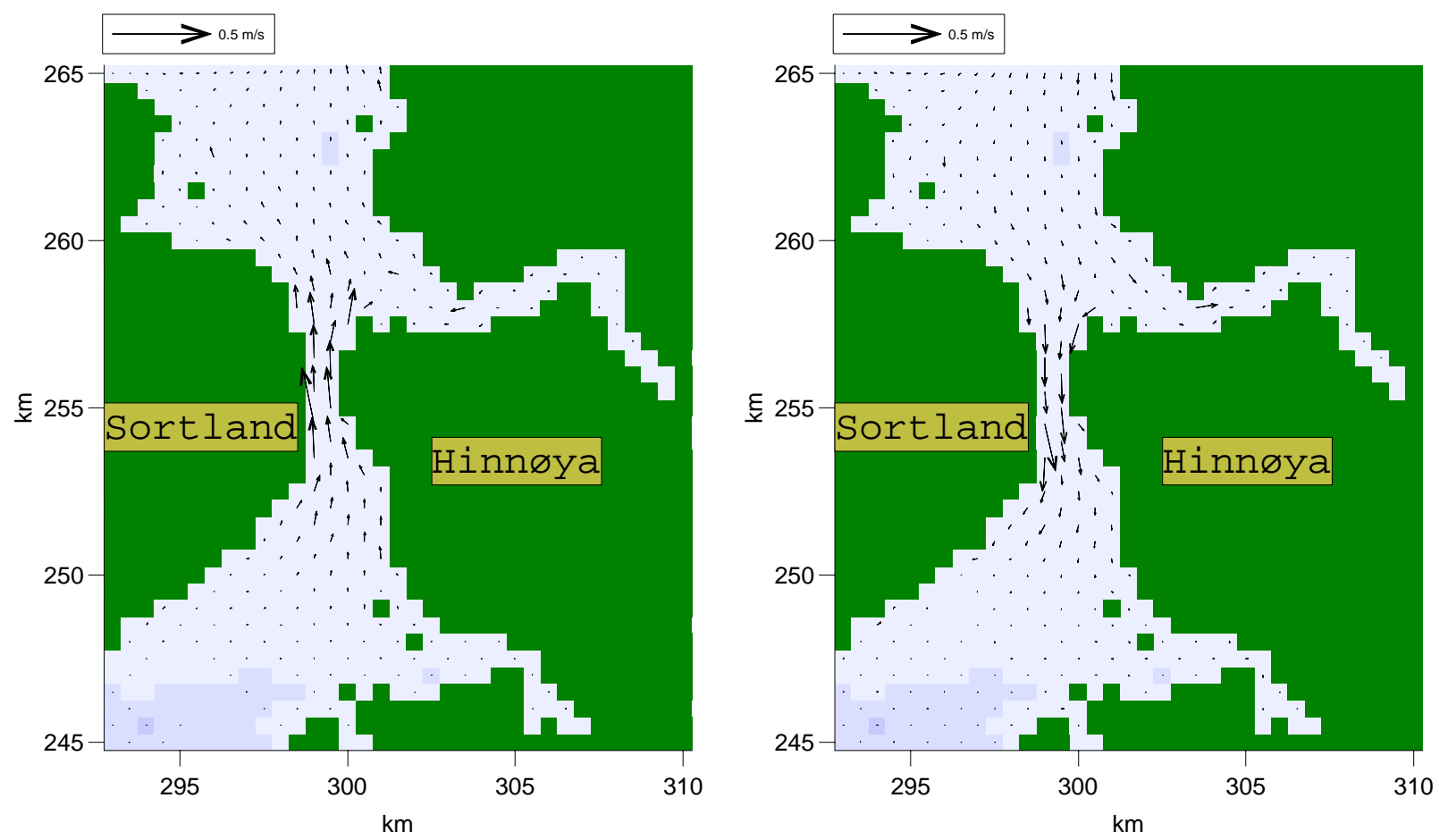

Figure 18: Left panel: Current field at the time of peak $M_{2}$ volume flux in northward direction in Sortlandsundet between coordinates $(297,254)$ and $(302,254)$. Right panel: Current field at the time of peak $M_{2}$ volume flux in southward direction.
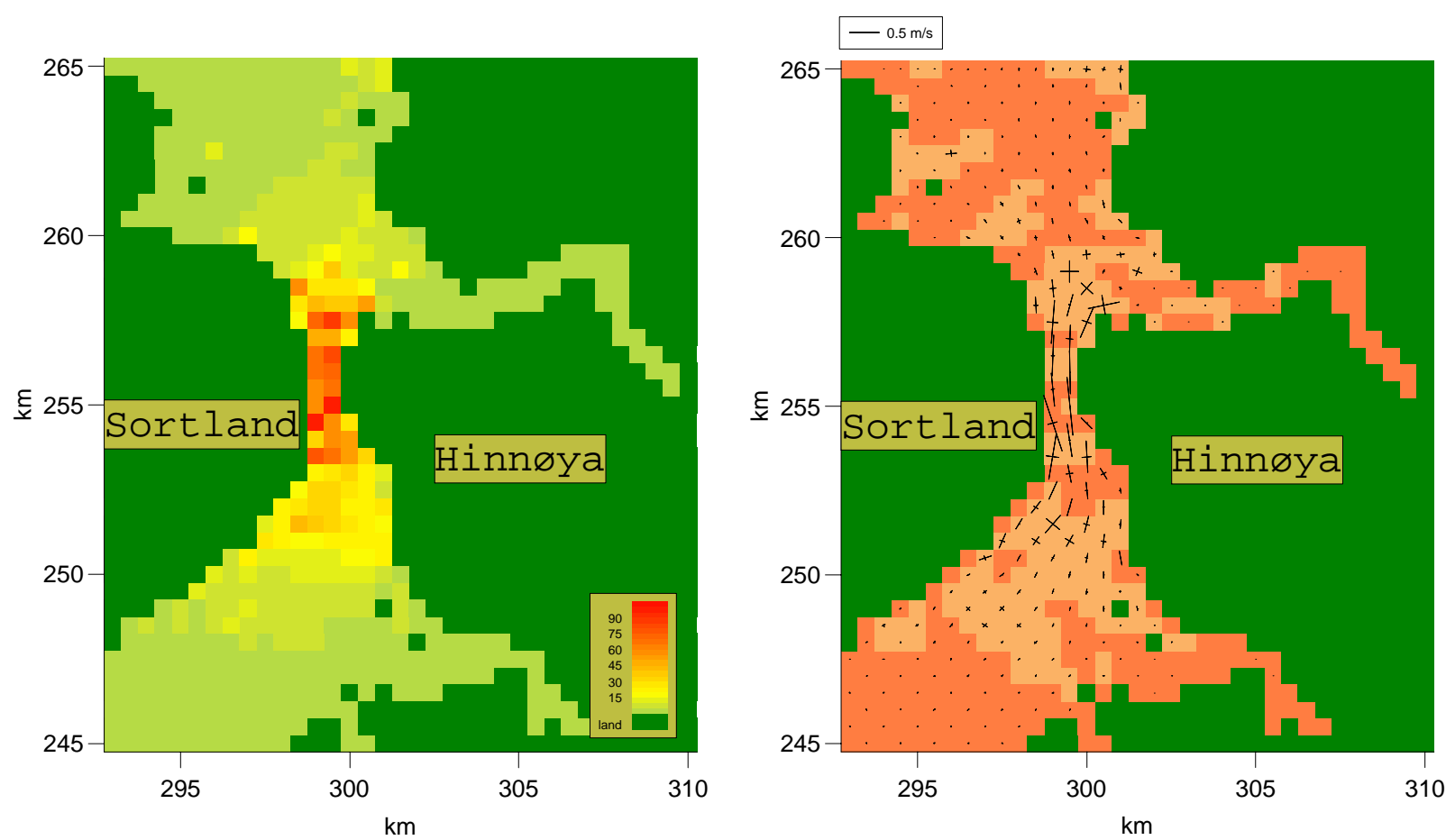

Figure 19: Left panel: Maximum $K_{1}$ current (major half axis) in Sortlandsundet. Color scale in $\mathrm{cm} / \mathrm{s}$, legend. Right panel: The rotation of the $K_{1}$ current vector. Bright shadowing depicts region with clockwise rotation, darker shadowing counterclockwise rotation. The crosses show the major and minor axes. 

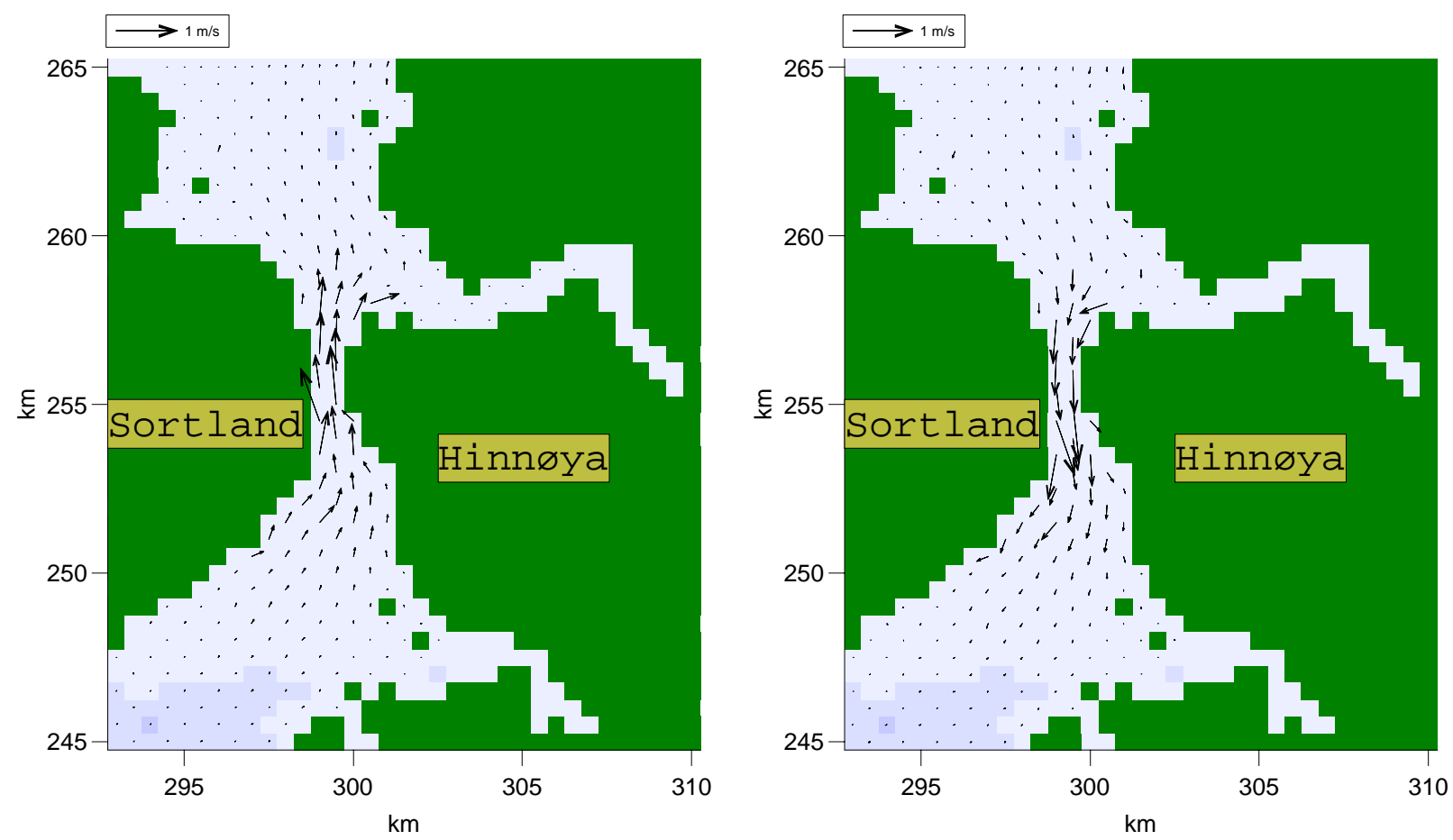

Figure 20: Left panel: Current field at the time of peak $K_{1}$ volume flux in Sortlandsundet between coordinates $(297,254)$ and $(302,254)$. Right panel: Current field at the time of peak $K_{1}$ volume flux in southward direction.

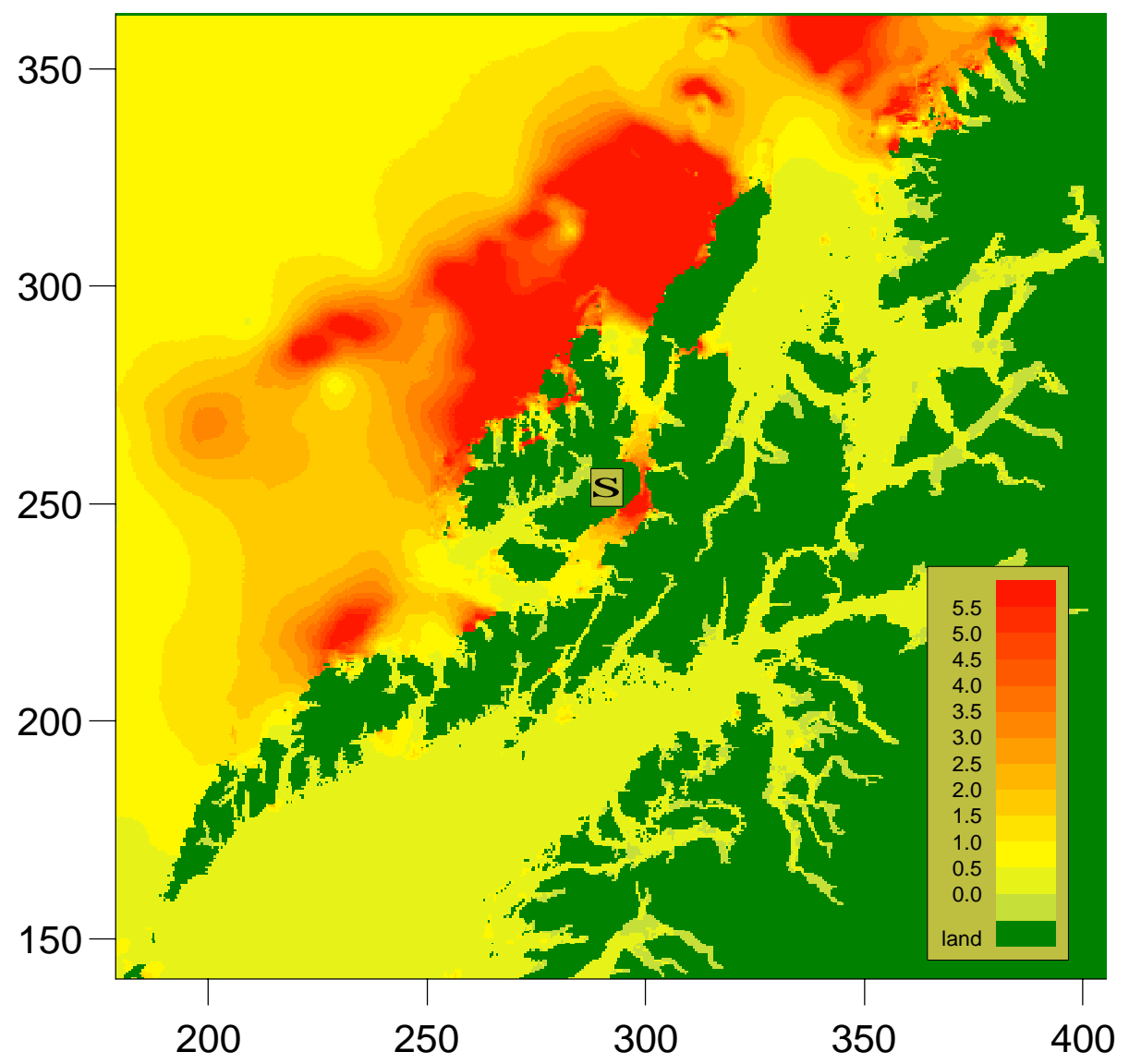

Figure 21: The ratio between the major axes of the current ellipses for the $K_{1}$ and $M_{2}$ components. Sortlandsundet (S) in the center. Color scale in legend. 


\subsubsection{The Gims $\varnothing y$ channel}

The Gimsøy channel is located between the Lofoten islands Vestvågøy and Austvågøy with the island Gimsøy in the middle. A strong current, Gimsøystraumen, runs in the narrows between Gimsøy and Austvågøy and another current, Sundklakkstraumen, in the narrow channel between Gimsøy and Vestvågøy.

In figure 22 the modelled current is depicted by its peak values and by the current ellipses. A complex pattern is visible in the rotation of the current vector, with strong currents in Sundklakkstraumen and Gimsøystraumen. The two available stations with current measurements, G1 and G2 (table 8 and figure 11), are located in Gimsøystraumen. The model results shown in table 8 are comparable to the observed, but with a $500 \mathrm{~m}$ grid resolution in the narrow channel representative grid positions for the stations are difficult to obtain. We have used data from the nearest grid point with approximately the same depth as in the measurement station.

The pilot book, Norwegian Hydrographic Service (1986a), predicts maximum northward current in Gimsøystraumen approximately one hour after high water running with a speed of $231 \mathrm{~cm} / \mathrm{s}$ at spring. Based on the calculated volume flux for $M_{2}$ the model predicts a maximum northward current in Gimsøystraumen of $115 \mathrm{~cm} / \mathrm{s}$ (figure 24) approximately one hour after high water. Correspondingly the combined effect of $M_{2}$ and $S_{2}$ is $158 \mathrm{~cm} / \mathrm{s}$ while $M_{2}+S_{2}+N_{2}+K_{1}$ gives $233 \mathrm{~cm} / \mathrm{s}$. Figure 23 shows the current field at the time of peak $M_{2}$ volume flux in northward and southward direction.
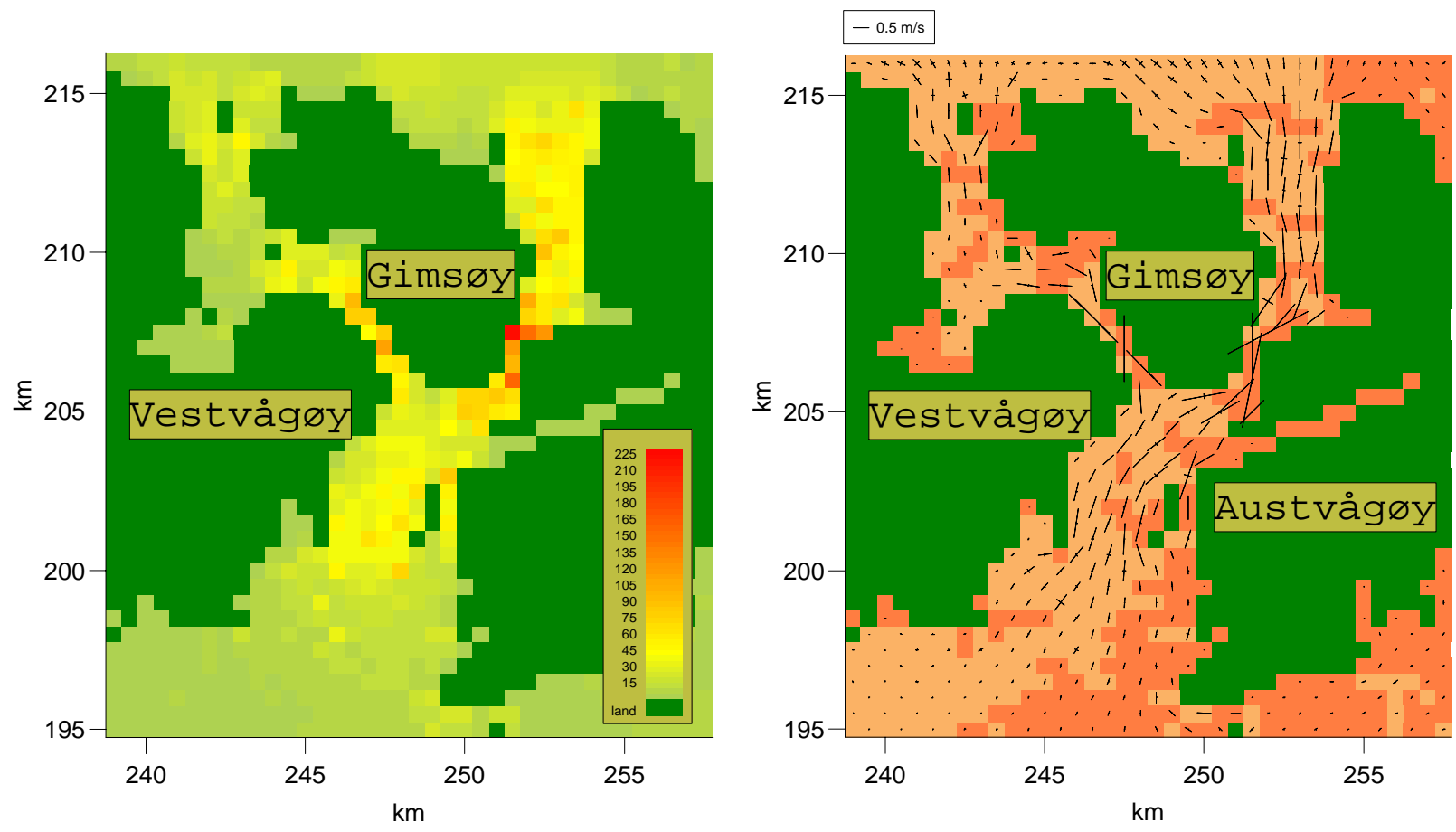

Figure 22: Left panel: Maximum $M_{2}$ current (major half axis) in Gimsøystraumen. Color scale in $\mathrm{cm} / \mathrm{s}$, legend. Right panel: Tidal ellipse and rotation of the $M_{2}$ current vector. Bright shadowing clockwise rotation, darker shadowing counterclockwise. The crosses show the major and minor axes. 
Table 8: Parameters for the $M_{2}$ current ellipse. A $(\mathrm{cm} / \mathrm{s})$, major half axis; B $(\mathrm{cm} / \mathrm{s})$, minor half axis; $\theta$ (deg.), orientation of major axis in degrees true; Rot., rotation direction for the current vector ( + , clockwise; -, counterclockwise).

\begin{tabular}{|l|r|r|r|c|r|r|r|c|}
\hline \multirow{2}{*}{$\begin{array}{l}\text { Station } \\
\text { (map code) }\end{array}$} & \multicolumn{4}{|c|}{ Observed } & \multicolumn{4}{|c|}{ Model } \\
\cline { 2 - 9 } & $\mathrm{A}$ & $\mathrm{B}$ & $\theta$ & Rot. & $\mathrm{A}$ & $\mathrm{B}$ & $\theta$ & Rot. \\
\hline G1 & 83.3 & 1.2 & 216 & - & 118.0 & 0.0 & 0 & non \\
\hline G2 & 113.9 & 12.6 & 41 & - & 71.0 & 3.0 & 68 & - \\
\hline
\end{tabular}
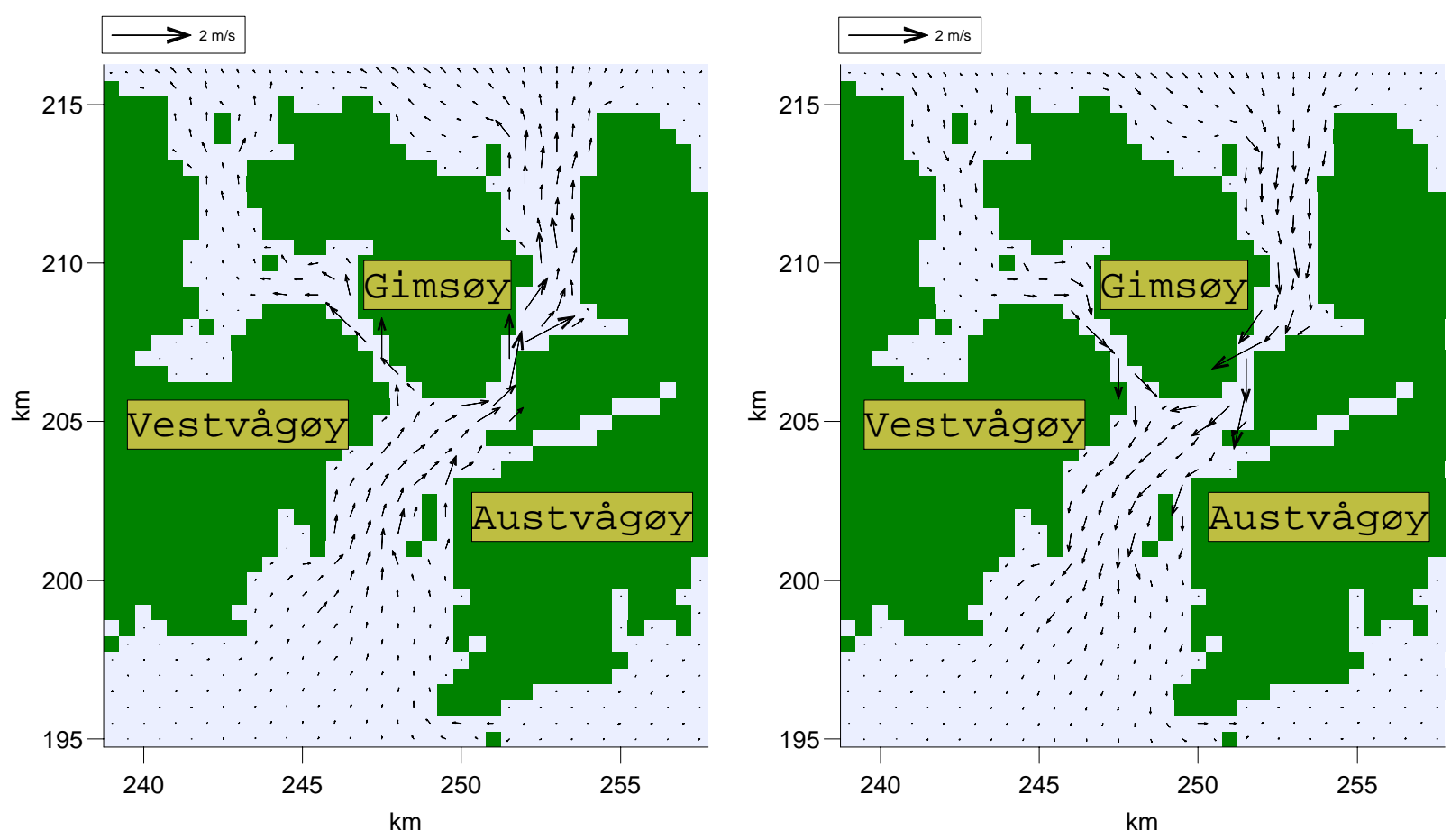

Figure 23: Left panel: Current field at the time of peak $M_{2}$ volume flux in northward direction in broad channel between coordinates $(245,203)$ and $(252,203)$. Right panel: Current field at the time of peak $M_{2}$ volume flux in southward direction.

The modelled maximum $M_{2}$ current is in fair agreement with observations from stations G1 and G2, table 8. Based on the calculated volume flux in Sundklakkstraumen between coordinates $(245,207)$ and $(250,207)$, a slightly slower $M_{2}$ mean current of $1.0 \mathrm{~m} / \mathrm{s}$ is found.

The major axis of the $M_{4}$ component (period 6.2 hours), which is due to nonlinear interaction, is measured to be $13.6 \mathrm{~cm} / \mathrm{s}$ at 5 meter depth at station G1. In our model with only nonlinear bottom friction terms included, a smaller $M_{4}$ current of about 4 $\mathrm{cm} / \mathrm{s}$ is found in the same location. This indicates that nonlinear advection terms are of importance in this region. 


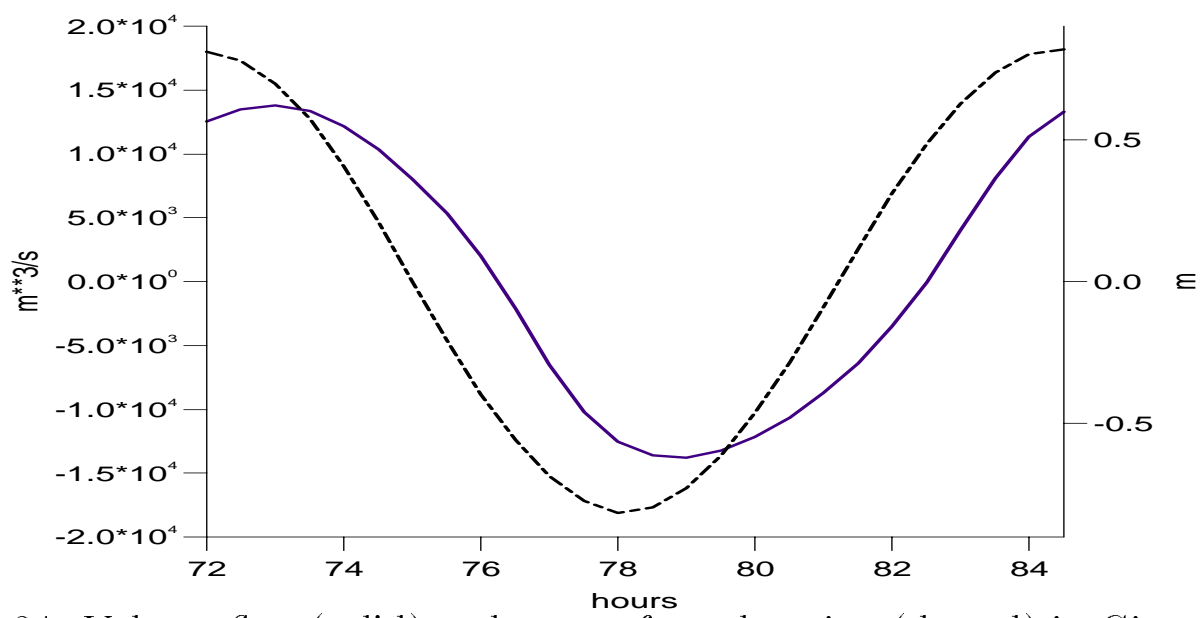

Figure 24: Volume flux (solid) and sea surface elevation (dotted) in Gimsøystraumen, cross-section between coordinates $(250,207)$ and $(253,207)$. The area of this crosssection is $12000 \mathrm{~m}^{2}$ leading to a mean peak northward current of $115 \mathrm{~cm} / \mathrm{s}$

\subsubsection{Visual observation of current shift}

During the period 12-14 July 1996 one of the authors (Gjevik) observed visually the shift in direction of the tidal current in Gimsøystraumen and Sundklakkstraumen, (see section 4.2.4). He also made similar observations in two other channels, Nappstraumen and Sundstraumen, further west in Lofoten. The time of the current shift, i.e slack water, were estimated following the drift of markers (sea weed, jellyfish etc.) floating in the surface. In Gimsøystraumen and Sundklakkstraumen the bridges across provided convenient platforms for the observations. The drift of the markers could not be estimated well unless the current was above a certain level. The fact that the current did not turn simultaneously across the channel made it difficult to estimate the exact time of the turning. In most cases it was only possible to determine the time of turning within an interval of 30-60 minutes for slack water. The observations are compared with the predicted time of current shift in the channels from a model simulation including all four components $M_{2}, S_{2}, N_{2}$, and $K_{1}$ (table 9 ). In view of the relatively large uncertainty in the observational data the agreement with model prediction is good.

Table 9: Observed and modelled time (UTC) for slack water 12-14 July 1996

\begin{tabular}{|l|l|c|c|c|c|c|}
\hline \multirow{2}{*}{ Location } & \multicolumn{2}{|c|}{12 July } & \multicolumn{2}{c|}{13 July } & \multicolumn{2}{c|}{14 July } \\
\cline { 2 - 6 } & $\begin{array}{c}\text { Mod } \\
\text { Time Dir. }\end{array}$ & $\begin{array}{c}\text { Obs } \\
\text { Time }\end{array}$ & $\begin{array}{c}\text { Mod } \\
\text { Time Dir. }\end{array}$ & $\begin{array}{c}\text { Obs } \\
\text { Time }\end{array}$ & $\begin{array}{c}\text { Mod } \\
\text { Time Dir. }\end{array}$ & $\begin{array}{c}\text { Obs } \\
\text { Time }\end{array}$ \\
\hline Gimsøystraumen & $1330 \mathrm{NE} \rightarrow \mathrm{SW}$ & $1300-1400$ & $0845 \mathrm{SW} \rightarrow \mathrm{NE}$ & $0805-0835$ & & \\
$(226,206)$ & $1945 \mathrm{SW} \rightarrow \mathrm{NE}$ & $1910-1930$ & & & \\
Sundklakkstraumen & $1230 \mathrm{~N} \rightarrow \mathrm{S}$ & $1200-1300$ & $0745 \mathrm{~S} \rightarrow \mathrm{N}$ & $0725-0850$ & & \\
$(247,207)$ & $1900 \mathrm{~S} \rightarrow \mathrm{N}$ & $1930-1925$ & & & & \\
Nappstraumen & & & $1445 \mathrm{NE} \rightarrow \mathrm{SW}$ & $1430-1445$ & & \\
$(218,194)$ & & $2045 \mathrm{SW} \rightarrow \mathrm{NE}$ & $2000-2125$ & & \\
Sundstraumen & & & & & $1345 \mathrm{NW} \rightarrow \mathrm{SE}$ & $1240-1320$ \\
$(205,182)$ & & & & & $1945 \mathrm{SE} \rightarrow \mathrm{NW}$ & -2100 \\
\hline
\end{tabular}




\section{Concluding remarks}

The high resolution depth integrated model is found to reveal important features of the dynamics of the tides around The Lofoten Islands. Due to the bottom topography of the shelf and the geometry of the coastline a characteristic variation in tidal amplitude is found with relatively larger amplitudes south of the islands than north of the islands where the shelf is narrow. This large scale variation in sea level amplitude and phase for the three semi-diurnal constituents $M_{2}, S_{2}$, and $N_{2}$ is in good agreement with observations. For the main diurnal component $\left(K_{1}\right)$, with sea level amplitude of about one tenth of the dominant semi-diurnal component $\left(M_{2}\right)$, the difference between model and observation is larger. The simulations show that the diurnal tide transform into shelf wave modes on the narrow shelf north of The Lofoten Islands leading to a dominance of the diurnal current component in this area of the shelf and in some channels along the coast. This surprising result is also confirmed by measurements. Although the agreement between model and observation are generally very good we have seen systematic deviations, specially for the diurnal component, which can be improved with the use of optimization techniques.

The success of the model in predicting the speed and the time of shift of the current in main channels between The Lofoten Islands show that the local tidal conditions are to a large extent determined by the large scale dynamics of the tide in deep water where non-linear effects are negligible. In order to simulate the current field in channels with strong tidal current turbulence, flow separation and eddy formation need to be represented in a more realistic way in the model. This will require use of adaptive grid or nesting of finer grid models in certain areas. Also, particularly at certain times of the year, density stratifications may have a considerable effect on the tidal current and need therefore to be incorporated in the model in order to provide accurate prediction of currents.

Despite these limitations the results of the simulations with this barotropic tidal model stand by their own right and could serve as a starting point for more advanced modelling exercises and as a guidance for future measurement programs.

\section{Acknowledgements}

We are grateful to the Norwegian Hydrographic Service for getting access to their data archive on sea level and current records and to S. Sundby at Institute of Marine Research Bergen and S. Myking at Geophysical Institute University of Bergen for processing data records of current from the Moskenes sound for us. The assistance by O. Høvik, T. Sjølie, I. Fossum, J. Gjevik and E. Onsum in generating a high resolution depth matrix for the area is greatly appreciated. This work has also received support from The Research Council of Norway, contracts 109228/122 MAREMI and 133102/431 BeMatA program. 


\section{References}

Adlandsvik, B., Sundby, S., 1994. Modelling the transport of cod larvea from the Lofoten area. ICES mar. Sci. Symp.

Davies, A. M., Jones, J. E., Xing, J., 1997a. Review of recent developments in tidal hydrodynamic modeling. I: Spectral models. Journal of Hydraulic Engineering 123(4), 278-292.

Davies, A. M., Jones, J. E., Xing, J., 1997b. Review of recent developments in tidal hydrodynamic modeling. II: Turbulence energy models. Journal of Hydraulic Engineering 123(4), 293-302.

Dokken, T. S., Wahl, T., 1995. ERS-1 SAR observations of tidal currents in the Moskenes Sound. Report 04882, Forsvarets Forskningsinstitutt, Kjeller, Norway.

Eggvin, J., 1932. Vannlagene på fiskefeltene. Arsberetning Norges Fiskerier, Bergen, Norway 2, 90-95.

Eggvin, J., 1934. De oceanografiske forhold i Vestfjorden og deres sammenheng med lofotfisket 1933. Arsberetning Norges Fiskerier, Bergen, Norway 2, 94-102.

Furnes, G. K., Sundby, S., 1981. Upwelling and wind induced circulation in Vestfjorden. In R. Sætre and M. Mork (Eds.), The Norwegian Coastal Current, Volume 1 of Proceedings from the Norwegian Coastal Current Symposium, Geilo, pp. 152177. University of Bergen, Norway.

Geyer, W. R., 1993. Three-Dimensional tidal flow around headlands. Journal of Geophysical Research 98(1), 955-966.

Gjevik, B., 1990. Model simulations of tides and shelf waves along the shelves of the Norwegian-Greenland-Barents Seas. In A. M. Davies (Ed.), Modelling Marine Systems, Volume 1, pp. 187-219. CRC Press Inc.

Gjevik, B., 1998. Moskstraumen myter, diktning og virklighet. Annual proceeding of The Norwegian Academy of Science and Letters. Oslo, Norway.

Gjevik, B., Moe, H., Ommundsen, A., 1997. Sources of the Maelstrom. Nature $388(28), 837-838$.

Gjevik, B., Nøst, E., Straume, T., 1990. Atlas of tides on the shelves of the Norwegian and the Barents Seas. Report FoU-ST 90012, Department of Mathematics, University of Oslo.

Gjevik, B., Nøst, E., Straume, T., 1994. Model simulations of the tides in the Barents Sea. Journal of Geophysical Research 99(C2), 3337-3350.

Gjevik, B., Straume, T., 1989. Simulations of the $M_{2}$ and the $K_{1}$ tide in the Nordic Seas and the Artic Ocean. Tellus A(41), 73-96.

Jenserud, T., 1995. Rocky Water 93/10B-A synoptic CTD data set. FFI/Notat 95/00749, The Norwegian Defense Research Establishment.

Jenserud, T., 1996. Synoptic CTD measurements in Vestfjorden. FFI/Rapport 96/04160, The Norwegian Defense Research Establishment. 70 pp.

Lardner, R. W., 1993. Optimal controll of open boundary conditions for a numerical tidal model. Computer Methods In Applied Mechanics and Enginering 102, 367387. 
Lønseth, L., Schjølberg, P., 1993. Miljøforhold i Norskehavet; Vesterålen. Year Report 49570, Oceanor, Trondheim, Norway.

Maddock, L., Pingree, R. D., 1978. Numerical simulation of the Portland tidal eddies. Estuarine and Coastal Marine Science 6, 353-363.

Martinsen, E. A., Engedahl, H., 1987. Implementation and testing of a lateral boundary scheme as an open boundary condition in a barotropic ocean model. Coastal Engineering 11, 603-627.

Martinsen, E. A., Gjevik, B., Røed, L. P., 1979. A numerical model for long barotropic waves and storm surges along the western coast of Norway. Journal of Physical Oceanography 9(6), 1126-1138.

McClimans, T. A., Nilsen, J. H., 1991. Laborarory simulations of ocean circulation around Lofoten from October 1982 to June 1984. Report STF60 A91027, SINTEF/NHL, Trondheim, Norway, 7034 Trondheim, Norway.

Melsom, A., 1997. Ocean circulation in Vestfjorden. Research Report 57, Norwegian Meteorological Institute, P.O.Box 43 Blindern, Oslo, Norway.

Mesinger, F., Arakawa, A., 1976. Numerical methods used in atmospheric models. Global Atmosphere Research Programme(GARP) Publ. ser. WMO 17, 64 pp.

Mitchelson-Jacob, E. G., 1995. The oceanography of Vestfjorden, Norway based on the interpretation of 12 years of AVHRR imagery (1981-1992). Report U95-3, University of Wales, Bangor, Marine Science Laboratories, Menai Bridge, Wales, UK.

Moe, H., Gjevik, B., Ommundsen, A., 2000. A high resolution tidal model for the coast of Møre and Trøndelag, Mid Norway. Preprint Series, Department of Mathematics, University of Oslo..

Neef, B. J., 1999, June. Ocean wave analysis of Moskstraumen. Department of Mathematical Sciences, 75800 Mathematical Project 2, NTNU, Norway.

Norwegian Hydrographic Service 1986a. Pilot books for the Norwegian coast (4 ed.). Number 5 in Den Norske Los. Stavanger, Norway: Norwegian Hydrographic Service. ISBN 82-90653-02-6.

Norwegian Hydrographic Service 1986b. Pilot books for the Norwegian coast (4 ed.). Number 6 in Den Norske Los. Stavanger, Norway: Norwegian Hydrographic Service. ISBN 82-90653-05-0.

Norwegian Hydrographic Service 1998. Tide tables for the Norwegian coast and Svalbard (61 ed.). Stavavger, Norway: Norwegian Hydrographic Service.

Ommundsen, A., 1999. Models of cross shelf transport introduced by the Lofoten Maelstrom. Preprint Series, Department of Mathematics, University of Oslo.

Ommundsen, A., Gjevik, B., 2000. Propagation of tidal Kelvin waves along shelves which varies in along shelf direction. In progress.

Sverdrup, H. U., 1952. Havlære. Oslo, Norway: Fabritius \& Sønners Forlag.

Wahl, T., 1995. The Maelstrøm seen from space. Nordic Space Activities 2-3, 22-23. 